\title{
Enhancement in Specific Absorption Rate by Solvent Microencapsulation
}

\begin{tabular}{|r|l|}
\hline Journal: & AIChE Journal \\
\hline Manuscript ID & AIChE-18-20136.R1 \\
\hline Wiley - Manuscript type: & Research Article \\
\hline Date Submitted by the Author: & 16 -Jun-2018 \\
\hline Complete List of Authors: & $\begin{array}{l}\text { Moore, Thomas; University of Melbourne, Chemical Engineering } \\
\text { Mumford, Kathryn; University of Melbourne, Chemical \& Biomolecular } \\
\text { Engineering } \\
\text { Stevens, Geoffrey W; University of Melbourne, Chemical \& Biomolecular } \\
\text { Engineering } \\
\text { Webley, Paul; The University of Melbourne, Chemical and Biomolecular } \\
\text { Engineering; }\end{array}$ \\
\hline Keywords: & $\begin{array}{l}\text { Environmental engineering, Gas purification, Mass transfer, Materials, } \\
\text { Absorption }\end{array}$ \\
\hline \multicolumn{2}{|c}{} \\
\hline
\end{tabular}

\section{SCHOLARONE"}

Manuscripts

This is the author manuscript accepted for publication and has undergone full peer review but has not been through the copyediting, typesetting, pagination and proofreading process, which may lead to differences between this version and the Version of Record. Please cite this article as doi: 10.1002/aic.16366 


\title{
Enhancement in Specific Absorption Rate by Solvent
} Microencapsulation

\author{
Thomas Moore $^{1}$, Kathryn A. Mumford ${ }^{1}$, Geoffrey W. Stevens ${ }^{1}$, and Paul A. \\ Webley $^{* 1}$ \\ ${ }^{1}$ Department of Chemical Engineering, University of Melbourne, Melbourne, VIC, 3010, Australia
}

\begin{abstract}
Microencapsulation of liquid solvents (MECS) has been proposed as a means of increasing the rate of absorption in gas separation processes. Surface renewal theory was used to rigorously quantify the increase in absorption microencapsulation could provide, compared to traditional packed columns. The results indicate that, for chemical solvents, gas flux will be similar in the two cases, while for physical solvents gas flux into MECS may be larger, owing to the reduction in spatial scales. However, previous publications may have overestimated the increase in surface area that microencapsulation can provide by approximately 3-10 times. Internal fluid flow inside fluidised MECS was also studied, and it was found that gas flux will be similar for stationary and fluidised particles. Overall, microencapsulation can be expected to increase gas absorption rates by approximately an order of magnitude for chemical solvents, and up to 2 orders of magnitude for physical solvents.
\end{abstract}

Keywords: Absorption, Environmental Engineering, Gas Purification, Mass Transfer, Materials.

\section{Introduction}

Microencapsulation of liquid sorbents (MECS) is a novel approach to carbon capture, in which small droplets of solvent $(0.1-0.6 \mathrm{~mm}$ in diameter $)$ are encapsulated in thin spherical shells of a silicone

${ }^{*}$ Corresponding Author: Paul A. Webley, Department of Chemical Engineering, University of Melbourne, Melbourne, VIC, 3010, Australia.

Email: paul. webley@unimelb.edu.au 
material which is highly permeable to $\mathrm{CO}_{2} \cdot{ }^{1}$ Microencapsulation could in principle be applied to any solvent-based gas separation process, and it is fundamentally a solvent enabling technology. MECS particles can contain viscous, corrosive, volatile, precipitating, and possibly even toxic solvents, which are otherwise difficult to handle. Furthermore, MECS have very high specific surface areas (1-2 orders of magnitude greater than the liquid in a packed column) and so could allow solvents which absorb gas slowly to be used in unit operations of a practical size. The dual benefit of enhanced mass transfer and solvent immobilisation is particularly well suited to advanced solvents, such as ionic liquids or precipitating potassium carbonate systems, which typically have excellent thermodynamic properties, but which may be highly viscous, precipitate solids, or absorb $\mathrm{CO}_{2}$ slowly. ${ }^{2-4}$

Increased surface area is not the only difference between mass transfer in MECS and in traditional packed columns. As a liquid flows down a packed column it is continually mixed. This process carries spent solvent at the surface to the bulk and replaces it with fresh solvent, and this 'surface renewal' can increase the gas flux. ${ }^{5}$ On the other hand, in a MECS particle, the proximity of the capsule walls increases the significance of viscous forces, limiting radial fluid flow and surface renewal effects. Other differences include the shell of a MECS particle (which provides an extra layer of mass transfer resistance), ${ }^{6}$ differences in liquid holdup between the two operations, and the fact that, for the smallest MECS particles, absorption may be reaction controlled, in which case increasing the surface area does not further improve mass transfer. ${ }^{7}$

To date, only the simplest comparisons between gas absorption in microencapsulated sorbents and in traditional packed columns can be found in the literature. Raksajati et al. ${ }^{8}$ assumed that the mass transfer coefficient, $k_{L}$, for absorption into MECS could be calculated using a correlation valid for a packed column, but it is unclear whether these correlations can be applied to MECS particles, given the large differences in fluid flow patterns between the two operations. Both Vericella et al. ${ }^{1}$ and Stolaroff et al. ${ }^{4}$ compared the flux of gas into stationary MECS particles with the flux into a stationary liquid film with the same specific surface area as a liquid in a packed column. However they did not quantify how well a stationary liquid film models the liquid flowing down a packed column. Stolaroff et al. ${ }^{9}$ measured gas absorption into MECS containing ionic liquids and carbonate solutions inside a flow-though, fixed-bed absorber. They found that mass transfer rates were similar to those into static MECS particles, and were in good agreement with a simple resistance in series absorption model, however they did not seek to compare their system with a traditional operation. 


\section{Analysis of Mass Transfer}

\section{Mass Transfer into MECS}

Consider a gas brought into contact with a stationary MECS particle containing a liquid in which the gas is soluble, and in which it will undergo a reversible first order or pseudo-first order chemical reaction, with reaction rate constant $k$ (Figure 1). Then, if the gas phase is large and well mixed (so that the surface concentration remains constant), if the absorption is liquid-phase controlled (as is common for many processes; conditions for which this assumption is reasonable are discussed in section 4) and if convective liquid movement inside the particles can be ignored (see section 5) then the flux of gas into the MECS will quickly asymptote to the following, quasistatic value (see Bird, Stewart and Lightfoot ${ }^{10}$ and also Appendix I in the supplementary materials):

$$
J_{\mathrm{MECS}}=\alpha \Delta c \frac{\mathscr{D}}{r}(\phi \operatorname{coth} \phi-1)
$$

where $\Delta c \equiv c^{*}-\bar{c}$, in which $c^{*} \equiv H p_{\mathrm{CO}_{2}}$ is the concentration of unreacted gas which would be present at the solvent surface if the shell were removed (in general this will not equal the concentration at the outer polymer surface, as the shell and liquid will have different gas solubilities) and $\bar{c}$ is the concentration of unreacted gas at equilibrium with the bulk liquid composition. For irreversible 
systems $\bar{c}=0$, while for reversible systems $\bar{c}$ will tend to increase over time as the liquid becomes more saturated. $\alpha \equiv\left(c_{i}-\bar{c}\right) / \Delta c$ quantifies the significance of shell resistance, and

$$
\phi \equiv \sqrt{\frac{k r^{2}}{\mathscr{D}}}
$$

is the Thiele Modulus of the system, which quantifies the relative rates of diffusion and reaction ( $\phi \gg 1$ implies diffusion is slow relative to reaction, and vice versa for $\phi \ll 1$.) For an unsaturated, diffusion-controlled particle $(\phi \rightarrow \infty)$ with minimal shell resistance, Eq. (1) reduces to the much simpler:

$$
J=c^{*} \sqrt{\mathscr{D} k}
$$

Vericella et al. ${ }^{1}$ have demonstrated that, when shell resistance is accounted for, this expression is in good agreement with experimental data. The time required for the flux to asymptote to Eq. (3) (after, for example, a change in the external gas concentration) is on the order of $\min \left(r^{2} / \mathscr{D}, k^{-1}\right)$. As shown in the examples below, this is often much less than 1 second, and so even in an environment of variable gas concentration, the flux at any one time and location can often be well approximated by Eq. (3).

If these stationary MECS particles of radius $r$ were exposed to a gas in a unit operation with liquid holdup equal to $1-\varepsilon$ then the absorption rate of gas per unit volume of absorber would be equal to:

$$
\bar{R}_{\mathrm{MECS}}=J_{\mathrm{MECS}} \frac{3(1-\varepsilon)}{r}=\alpha(1-\varepsilon) k \Delta c\left(\frac{\phi \operatorname{coth} \phi-1}{\phi^{2} / 3}\right)
$$

Even though this expression was derived for stationary MECS particles, it will be shown in section 5 that it is also valid for MECS particles placed in a fluidised bed, as particle collisions would not generate enough liquid mixing to significantly affect the mass transfer rate. Note that in this work the liquid holdup is defined as the fraction of total absorber volume occupied by the liquid solvent (whether packing is present or otherwise) and the unit operation 'voidage', $\varepsilon$, is the fraction of remaining space occupied by the gas phase, any packing material, and the shells of the particles.

\section{Mass Transfer in a Packed Column}

Mass transfer inside a traditional packed column is considerably more complicated. The liquid surface area available for mass transfer is difficult to quantify, as is the effect of the mixing of the liquid as 
it flows over the packing material. At present a rigorous model of all transport phenomena occuring inside an absorption column is computationally infeasible. ${ }^{11}$ Instead, empirical equations have been developed which take into account both physical properties of the liquid (viscosity, gas diffusivity, etc.) and properties of the absorption process (packing type and size, Reynold's number, etc.) These equations predict a $k_{L}$ value, which is the liquid side mass transfer coefficient for a purely physical solvent, defined by

$$
J_{\text {Column }}^{\text {Physical }}=k_{L}\left(c^{*}-c_{\text {bulk }}\right) \approx k_{L}\left(c^{*}-c_{\text {av }}\right) .
$$

Here, $c_{\text {bulk }}$ is the concentration of gas in the bulk of the liquid, which in most cases can be taken to equal the mean composition of the whole liquid, $c_{\mathrm{av}}$, as the surface layer is typically much thinner than the liquid depth.

If the solute gas reacts with the flowing solvent, it can further enhance the mass transfer rate, and Eq. (5) is no longer valid. Many idealised mathematical models of the fluid flowing down an absorption column have been developed, and these can be used to relate the mass transfer enhancement due to reaction to the reaction kinetics, the physical properties of the liquid, and also the absorption rate under the same hydrodynamic conditions but with no reaction occuring, as quantified by $k_{L}$. The most popular are the surface renewal model of Danckwerts, ${ }^{12}$ the penetration theory of Higbie, ${ }^{13}$ and the two-film theory of Whitman. ${ }^{14}$ For a gas absorbed by a solvent with which it undergoes a reversible pseudo-first order chemical reaction, Danckwerts' surface renewal theory predicts the flux will be given by:

$$
J_{\text {Column }}=k_{L} \Delta c \sqrt{1+\frac{\mathscr{D} k}{k_{L}^{2}}}=k_{L} \Delta c \sqrt{1+\mathrm{Ha}^{2}}
$$

where $\mathrm{Ha} \equiv \sqrt{\mathscr{D} k} / k_{L}$ is the Hatta number for a pseudo-first order reaction, which represents the ratio of gas that reacts at the surface to gas that is convectively transported to the bulk. Even though the theories of Whitman and of Higbie are based on very different physical idealisations, their predictions for $J$ differ by less than 3\% over the whole range $0<\mathrm{Ha}<\infty$ (Figure 2); Danckwerts' expression was chosen for its algebraic simplicity.

The rate of absorption of gas per unit volume of absorber is given by:

$$
\bar{R}_{\text {Column }}=J_{\text {Column }} \cdot a=a k_{L} \Delta c \sqrt{1+\mathrm{Ha}^{2}}
$$


where $a$ is the effective liquid surface area available for mass transfer per unit volume of absorber.

\section{Mass Transfer Enhancement}

Eq. (1) to Eq. (7) can be used to compare mass transfer rates inside MECS particles and packed columns. In order to provide a fair comparison between the two technologies, it is assumed throughout that the mean driving force for mass transfer, $\Delta c$, is the same in each case (see the end of this section for further discussion of this point.) Processes in which the mean value of $\Delta c$ changes over time (such as a batch-wise fluidised bed process) are not considered in this analysis, as average values of $J_{\text {MECS }}$ and $\bar{R}_{\text {MECS }}$ are difficult to unambiguously define in such cases. On the other hand, $\Delta c$ will remain approximately constant in steady-state fluidised bed processes and in unsteady-state constant-pattern packed bed processes, and in these cases the average mass transfer rate into MECS and into a liquid in a packed column can be meaningfully compared. Under these conditions, the degree to which the mixing of the liquid inside a packed column enhances the gas flux, relative to the gas flux into a MECS particle, is given by:

$$
M \equiv \frac{J_{\text {Column }}}{J_{\mathrm{MECS}}}=\frac{1}{\alpha}\left(\frac{\phi}{\phi \operatorname{coth} \phi-1}\right) \sqrt{1+\mathrm{Ha}^{-2}}
$$

In the (physically common) limit of $\alpha \rightarrow 1$ and $\phi \rightarrow \infty$, this expression reduces to

$$
M=\sqrt{1+\mathrm{Ha}^{-2}}
$$

This is a physically reasonable result. Large Hatta numbers correspond to either a column with minimal liquid mixing (small $k_{L}$ values) or an intrinsically fast solvent (large $\sqrt{\mathscr{D} k}$ values, c.f. Eq. (3)). As remarked above, under these conditions most gas molecules react at the surface, and very few are carried to the bulk by the mixing of the liquid. Thus, when the Hatta number is large liquid mixing should have little effect on the gas flux, as predicted by Eq. (9). Conversely, liquid mixing is much more likely to be a significant factor for intrinsically slow solvents, for which convective transport to the bulk is more important.

Rather than comparing the flux of gas in a packed column with the flux into MECS, a fairer comparison would be to consider the specific absorption rate per unit volume of absorber, $\bar{R}$. MECS have very large specific surface areas, so the specific absorption rate could be large even if the gas 
flux is suppressed. The enhancement in specific absorption rate that MECS can provide is given by:

$$
\Gamma \equiv \frac{\bar{R}_{\mathrm{MECS}}}{\bar{R}_{\text {Column }}}=\left(\frac{\alpha(1-\varepsilon)}{\sqrt{1+\mathrm{Ha}^{-2}}}\left(\frac{k}{\mathscr{D} a^{2}}\right)^{1 / 2}\right)\left(\frac{\phi \operatorname{coth} \phi-1}{\phi^{2} / 3}\right)
$$

Though no single parameter can be constructed to unambiguously compare these two different technologies, the relative specific absorption rate, $\Gamma$, accounts for both the enhanced surface area of MECS, and any differences in mass transfer mechanisms and liquid holdup. In order to quantify $\Gamma$ a correlation is required for $k_{L}$ and for $a$ : these provide the base case against which the MECS technology can be compared. It is interesting to note that only the final term in Eq. (10) depends upon the radius of the particles; this term is plotted in Figure 3 (note that, with physical properties kept constant, $\phi$ can be considered a dimensionless radius.) In the limit as particles become very small $(\phi<0.1)$, the improvement provided by microencapsulation plateaus. At this point, the particles are so small that the absorption is reaction controlled, so further increases in surface area do not increase the absorption rate. Because the second term asymptotes to 1 as $\phi \rightarrow 0$, the maximal possible improvement MECS can provide is given by the first bracketed term in Eq. (10). For large particles $(\phi>10)$, the second term asymptotes to $3 / \phi$. Under these conditions, absorption is diffusion controlled, and $\Gamma$ is proportional to the specific surface area of the MECS. Eq. (10) can be rearranged to more clearly highlight the factors that contribute to the differences between $\bar{R}_{\text {Column }}$ and $\bar{R}_{\text {MECS: }}$ :

$$
\begin{aligned}
\Gamma & =\left[\frac{\alpha}{\sqrt{1+\mathrm{Ha}^{-2}}} \frac{\phi \operatorname{coth} \phi-1}{\phi}\right]\left[\frac{3(1-\varepsilon) / r}{a}\right] \\
& =\alpha \times\left(\frac{1}{\alpha M}\right) \times\left(\frac{a_{\mathrm{MECS}}}{a}\right) \\
& =\alpha \times\left(\frac{1}{\alpha M}\right) \times\left(\frac{a_{\mathrm{MECS}}^{\prime}}{a^{\prime}}\right) \times\left(\frac{1-\varepsilon}{h}\right)
\end{aligned}
$$

In Eq. (12), $\Gamma$ is divided into three factors - the effect of shell resistance, $\alpha$, the effect of suppression of liquid motion, $1 / \alpha M$, and the relative specific surface area on a unit volume basis, $a_{\mathrm{MECS}} / a$. In Eq. (13), this last term is further broken down into the relative specific surface area on a volume of solvent basis and the relative liquid holdup inside each unit operation.

In order to calculate the relative specific absorption rate, $\Gamma$, it was assumed that the mean driving force for mass transfer, $\Delta c$, was the same for both MECS-based systems and traditional packed columns. In reality this is unlikely to be the case, as the mean $\Delta c$ value depends upon the process 
design and the internal gas and liquid flow patterns in a complex way. However, there is always a tradeoff between reducing $\Delta c$ to minimise irreversibility and maximise the cyclic solvent capacity, and maximising $\Delta c$ to minimise absorber volume. If the mean value of $\Delta c$ is different in the two cases, the process with greater $\Delta c$ will only improve its kinetic performance at the cost of reduced thermodynamic efficiency or greater solvent circulation rates. An extreme example of this is a singlestage fluidised bed operation, in which severe solid back-mixing increases $\Delta c$, but only at the cost of low solid conversion and large circulation rates. Thus, in order to fairly evaluate the kinetic enhancement microencapsulation can provide, it should be assumed that the MECS-based process and the traditional absorption column are designed so that the mean driving force is identical for each case. Alternatively, if the mean $\Delta c$ values are not identical, $\Gamma$ may be considered the reduction in overall mass transfer resistance microencapsulation can provide, rather than the increase in absorption rate per unit volume of absorber.

\section{Alternative Reaction Mechanisms}

The derivation of a time-independent expression for $\bar{R}_{\text {MECS }}$, and hence for $\Gamma$, is only possible when the concentration of the reactive species remains homogeneous in space (as occurs in the case of diffusion with pseudo-first order reaction.) When this is not the case, the flux into a static solvent is a function of time, and depends on the particle's history. In such cases the gas flux depends on the way in which the partial pressure of the gas changes over time, which in turn depends in a complex way on the nature of the gas-liquid contacting equipment. For psuedo-first order reactions, however, the only condition is that the partial pressure of gas not change too quickly: provided partial pressure fluctuations have periods substantially longer than $\mathscr{O}\left(\min \left(r^{2} / \mathscr{D}, k^{-1}\right)\right)$, the flux will be well approximated by the asymptotic expression Eq. (1).

The restriction to solvents which undergo first order or pseudo-first order reactions is not as limiting as it may at first seem. Such solvents are very common industrially: when the concentration of the reactive species in a solvent is much greater than the physical concentration of dissolved gas, a pseudo-first order approximation is often valid, even if the fundamental reaction kinetics are of a different order in the reactive species (e.g. $\mathrm{CO}_{2}$ absorption into $\mathrm{K}_{2} \mathrm{CO}_{3}$ solutions). ${ }^{12}$ In such cases the concentrations of any reactive species in the solvent change slowly enough for spatial inhomogeneities to be smoothed out, and they can be lumped into a single, pseudo-first order rate constant. 
This rate constant may change over time as the reactive species are slowly depleted.

On the other hand, purely physical solvents do not exhibit pseudo-first order behaviour under any conditions. However, they are widely used in industry, and it would be useful to extend the above analysis to this common case. Furthermore, the analysis above suggests that the suppression of liquid mixing is particularly significant for solvents with slow reactions: when the Hatta number is small, convective transport to the bulk is much more significant than surface reactions. Physical solvents could be considered the limiting case of slow reactions, and so the suppression of liquid mixing inside MECS which contain physical solvents could be much more significant than for chemically reactive systems.

While the analytic approach taken above is impossible here (in general the flux into a MECS particle containing a physical solvent, $J_{\text {MECS }}^{\text {Physical }}$, is a function of time and also the particle's history), it is well known that, for spherical solid particles which adsorb gas, the gas flux can be well approximated by the linear driving force (LDF) model. Despite its simplicity, this model appears capable of capturing most of the important dynamic behaviour of solid adsorbent particles, and it has been used in the design of both packed beds ${ }^{15}$ and fluidised beds. ${ }^{16}$ When applied to a static MECS particle containing a physical solvent (which is governed by the same diffusion equation) the LDF model gives:

$$
J_{\mathrm{MECS}}^{\text {Physical }}=k_{\mathrm{LDF}}\left(c_{i}-c_{\mathrm{av}}\right)=\alpha^{\prime} k_{\mathrm{LDF}}\left(c^{*}-c_{\mathrm{av}}\right)
$$

where $\alpha^{\prime} \equiv\left(c_{i}-c_{\mathrm{av}}\right) /\left(c^{*}-c_{\mathrm{av}}\right)$ once again quantifies the shell resistance. Glueckauf ${ }^{17}$ suggested that $k_{\mathrm{LDF}} \approx 5 \mathscr{D} / r$, and other researchers have found this to be a useful (if slightly conservative) value. ${ }^{15,18}$ Substituting this into Eq. (14) gives:

$$
J_{\mathrm{MECS}}^{\text {Physical }}=\frac{5 \alpha^{\prime} \mathscr{D}}{r}\left(c^{*}-c_{\mathrm{av}}\right) .
$$

Eq. (15) can now be directly compared with Eq. (5), to calculate the degree to which liquid mixing enhances the gas flux, and to calculate the enhancement in specific absorption rate that can be achieved. Following the same procedure, and again assuming that the driving force, $\left(c^{*}-c_{\mathrm{av}}\right)$, is the same for a process utilising MECS and a traditional packed column:

$$
M_{\text {Physical }}=\frac{J_{\text {Column }}^{\text {Physical }}}{J_{\text {MECS }}^{\text {Physical }}}=\frac{k_{L} r}{5 \alpha^{\prime} \mathscr{D}}
$$




$$
\Gamma_{\text {Physical }}=\frac{\bar{R}_{\mathrm{MECS}}^{\text {Physical }}}{\bar{R}_{\text {Column }}^{\text {Physical }}}=\frac{J_{\text {MECS }}^{\text {Physical }}}{J_{\text {Column }}^{\text {Physical }}} \cdot \frac{3(1-\varepsilon) / r}{a}=\frac{15 \alpha^{\prime}(1-\varepsilon) \mathscr{D}}{r^{2} k_{L} a}
$$

It is interesting to observe that the flux in Eq. (15) is dependent on the particle radius, and is larger for smaller particles. This is in contrast to MECS containing chemically reactive solvents in the diffusion-controlled regime, for which the flux is independent of particle radius. For diffusioncontrolled chemical solvents, the characteristic spatial scale over which the concentration changes is the thickness of the thin surface layer inside which gas reacts away. This is of order $\sqrt{\mathscr{D} / k}$, and is independent of particle radius. ${ }^{5}$ On the other hand, for physical solvents, the characteristic spatial scale is the radius $r$, and smaller particles will have larger concentration gradients than larger particles with the same degree of saturation. That the flux should scale with $1 / r$ can be seen by nondimensionalising the spherical diffusion equation for a particle placed in an environment of constant partial pressure. The time-evolution of this system is governed by:

$$
\partial_{t} c=r^{-2} \partial_{r}\left(\mathscr{D} r^{2} \partial_{r} c\right)
$$

and consider the simplest boundary conditions: $c=c_{0}$ at $t=0$ and $c=c_{i}$ for $t>0$ at the liquid surface. Then the dimensionless time takes the form:

$$
\bar{t}=\frac{t}{r^{2} / \mathscr{D}}
$$

and so, all else being equal, the time to achieve some arbitrary degree of saturation, $t_{\text {sat }}$, scales with $r^{2}$. Because the total number of moles of gas absorbed, $\Delta n$, scales with $r^{3}$, the rate of gas absorption into a single particle scales as $\Delta n / t_{\mathrm{sat}} \propto r$. As the surface area scales with $r^{2}$, the gas flux scales with $1 / r$, and is larger for smaller particles.

Thus, for the case of physical solvents, decreasing particle size has two potential benefits: it increases the specific surface area, and, by reducing spatial scales (and hence increasing the magnitude of all concentration gradients) it can also lead to higher gas flux. It is unclear at present whether suppression of liquid mixing will be as significant as either of these effects. 


\section{Shell Resistance}

The effect of shell resistance was analysed by Vericella et al., ${ }^{1}$ and was found to be minor $(\alpha \approx 0.9)$ for large ( $\sim 400 \mu \mathrm{m}$ diameter capsules) containing a $\mathrm{K}_{2} \mathrm{CO}_{3}$ solution. They modelled absorption into MECS as a resistance in series problem, so that

$$
\alpha=\frac{\mathscr{R}_{\text {solvent }}}{\mathscr{R}_{\text {solvent }}+\mathscr{R}_{\text {shell }}}
$$

where resistance is defined by $\mathscr{R}=\Delta c / J$; solvent-side resistances are given by the expressions described previously. From Eq. (1), for solvents undergoing a pseudo-first order reaction,

$$
\mathscr{R}_{\text {solvent }}=\left[\frac{\mathscr{D}}{r}(\phi \operatorname{coth} \phi-1)\right]^{-1}
$$

and from Eq. (15), for physical solvents,

$$
\mathscr{R}_{\text {solvent }}=\frac{r}{5 \mathscr{D}}
$$

For a spherical shell, the resistance takes the form (see Appendix II in the supplementary materials)

$$
\mathscr{R}_{\text {shell }}=\frac{H z}{\mathscr{P}_{\text {shell }}} \frac{r}{r+z}
$$

where $\mathscr{P}_{\text {shell }}$ is the shell permeability, and $z$ its thickness. $\alpha$ primarily depends on the shell thickness (which can vary from $10-50 \mu \mathrm{m}$ ) and the rate at which the neat solvent absorbs the gas.

\section{Example Systems}

To illustrate the results of the analysis, it is applied to two solvent systems for the absorption of carbon dioxide: a $30 \mathrm{wt} \% \mathrm{~K}_{2} \mathrm{CO}_{3}$ solution, and Selexol. These systems are widely used industrially, and are chemical and physical solvents respectively. 


\section{Potassium Carbonate for Carbon Capture}

The original context in which MECS were developed was the encapsulation of carbonate solutions for $\mathrm{CO}_{2}$ capture. ${ }^{6}$ Carbonate solutions are an obvious candidate for microencapsulation: they have favourable thermodynamic properties, but absorb $\mathrm{CO}_{2}$ slowly and may precipitate bicarbonate at high loadings. Concentrated carbonate solutions react with $\mathrm{CO}_{2}$ to produce bicarbonate:

$$
\begin{gathered}
\mathrm{CO}_{2}+\mathrm{OH}^{-} \longrightarrow \mathrm{HCO}_{3}^{-} \\
\mathrm{H}_{2} \mathrm{O}+\mathrm{CO}_{3}^{2-} \rightleftharpoons \mathrm{HCO}_{3}^{-}+\mathrm{OH}^{-}
\end{gathered}
$$

The carbonate/bicarbonate buffer ensures the $\mathrm{pH}$ remains around 9-10, and because Eq. (25) may be regarded as instantaneous, hydroxide ions are constantly supplied for Eq. (24), at a concentration that only depends on the $\left[\mathrm{HCO}_{3}^{-}\right] /\left[\mathrm{CO}_{3}^{2-}\right]$ ratio. ${ }^{5}$ In concentrated carbonate solutions the concentrations of $\mathrm{HCO}_{3}^{-}$and $\mathrm{CO}_{3}^{2-}$ change slowly enough to remain spatially homogeneous, so the system is governed by diffusion with pseudo-first order reaction. Unpromoted carbonate solutions represent a useful limiting case, in that they have slower kinetics than most CCS solvents with low enough viscosity to be used in a packed column (e.g. promoted carbonates, amine-based solvents). Thus they typically operate at relatively low Hatta numbers, and so the reduction in gas flux due to the suppression of liquid motion and surface renewal effects inside the small capsules (relative to liquid flowing down a traditional absorption column) will be more significant in these systems than in most others. An unpromoted $30 \mathrm{wt} \% \mathrm{~K}_{2} \mathrm{CO}_{3}$ system is considered below.

\section{Mass Transfer Correlations}

In order to evaluate the difference in gas flux, $M$, and the overall absorption rate, $\Gamma$, between a traditional packed column and MECS particles, a correlation for $k_{L}$ is required, along with an estimate of the specific liquid surface area, $a$. Many such correlations can be found in the literature (see, for instance, the review papers of Wang et al. ${ }^{19}$ and Hegely et al. ${ }^{20}$ ) Table 1 summarises a number of widely used correlations: the correlation of Shulman et al. $^{21}$ was recommended by Treybal ${ }^{22}$ (who also provided the correlation for $a$ based on Shulman's data); the correlation of Onda et al. ${ }^{23}$ has been widely used, ${ }^{24,25}$ and was recommended in Perry's Chemical Engineering Handbook; ${ }^{26}$ the correlation of Hanley and $\mathrm{Chen}^{27}$ is implemented in the popular ASPEN process simulation software, and 
both Rocha et al. ${ }^{28}$ and Billet and Shultes ${ }^{29}$ have been cited several hundred times. Even though these correlations have been widely used and recommended, a great deal of care must be taken when using them to assess enhancement factors associated with chemical reactions or (as in the present case) liquid mixing.

In Figure 4, the correlations of Onda, of Billet and Shultes, and of Shulman were each used to analyse a packed column containing 1/2-inch ceramic Raschig Rings, which would use a 30wt\% $\mathrm{K}_{2} \mathrm{CO}_{3}$ solution to remove $\mathrm{CO}_{2}$ from a flue gas stream (see Table 2 for the relevant material parameters). The correlations of Billet and Shultes and of Shulman et al. predict that suppression of liquid mixing inside MECS particles could decrease the gas flux by a factor of 2-4, while the Onda correlation predicts only a modest decrease. In the former case, suppression of liquid mixing would be a very significant factor, and the assumption of Vericella et al. ${ }^{1}$ and Stolaroff et al., ${ }^{4}$ that a static pool of liquid is a good model of the fluid in an absorber, would be inappropriate. If Onda et al. ${ }^{23}$ were trusted instead, the flux into MECS would be comparable with a packed column, and a static pool would be a reasonable model system. Figure 5 is a similar plot for a tower containing the structured packing Mellapak 500Y; the differences in the value of $\alpha M$ are less pronounced, but still significant.

In order to understand this discrepancy, the physical methods used to derive these correlations must be considered. It is clear from Figures 4 and 5 that the correlations give similar predictions for $k_{L} a$ but disagree on how this should be factored into $k_{L}$ and $a$ separately. Values for $a$ inside a packed column are difficult to measure experimentally, and many general-purpose correlations (such as Billet and Shultes ${ }^{29}$ ) are fitted to $k_{L} a$ data, which can force unrealistic values for $a .^{30}$ On top of these practical difficulties, there is also no universally accepted definition of $a$. Some authors define $a$ as the fraction of the total packing area that is covered in liquid. ${ }^{23}$ This definition does not take into account the fact that liquid trapped in pockets of packing can become saturated, and its surface area useless for gas absorption purposes. For this reason, some authors define $a$ as an effective area for mass transfer, calculated either by measuring $k_{G} a$ values (gas-side coefficients) in situations where $k_{G}$ is known, ${ }^{21}$ or by systematically varying $k$ (by adding a catalyst) and analysing the increase in $k_{L} a$ using surface renewal theories. ${ }^{5}$ The difficulty with these approaches is that the effective area depends upon the capacity of the solvent to absorb gas. Physical solvents with low gas solubility tend to saturate quite quickly, and so pockets of useless solvent form easily. Chemical solvents tend to have higher capacities relative to their absorption rates, so even stagnant pockets 
which trap liquid for long periods of time are likely to remain useful for gas absorption. In light of this, Danckwerts ${ }^{5}$ suggested that, for concentrated chemical solvents such as $30 \mathrm{wt} \% \mathrm{~K}_{2} \mathrm{CO}_{3}$, it is most appropriate to assume that all wetted area is useful for mass transfer, and so the effective area $a$ should be set equal to the entire wetted area of the packing. Thus for chemical solvents they recommended the Onda correlation be used instead of the Shulman correlation (which was correlated using physical absorption data.) This is supported by the fact that the wetted area predicted by Onda et al. closely matches the area predicted by Danckwerts and Sharma, ${ }^{36}$ who measured the effective area for absorption into a chemically reactive solvent.

Regarding structured packing, Tsai et al. ${ }^{30}$ found the general-purpose correlation of Rocha et al. ${ }^{28}$ gave incorrect predictions for aqueous systems (the errors in effective surface area were similar to those shown in Figure 5). It was suggested this could be because Rocha et al. used large amounts of data from distillation columns containing non-aqueous solutions. Hanley and $\mathrm{Chen}^{27}$ and Tsai et al. ${ }^{30}$ give quantitatively similar predictions, but Hanley and Chen's correlation predicts a decrease in area with increasing liquid velocity: an unintuitive result not found in most correlations. As Tsai et al. measured the surface area using a reactive aqueous solvent, their predictions would appear most applicable to the carbonate system.

Given that the correlations of Onda et al. and Tsai et al. provide the most appropriate measurements for $a$, Figures 4 and 5 show that the flux of $\mathrm{CO}_{2}$ into MECS containing $30 \mathrm{wt} \% \mathrm{~K}_{2} \mathrm{CO}_{3}$ will only be moderately less than the flux inside a packed column. Thus, in this case a static, thin layer of solvent is a reasonable model for the fluid inside an absorption column.

The addition of promoters to $\mathrm{K}_{2} \mathrm{CO}_{3}$ will increase the Hatta number, which will further reduce the effect of liquid mixing. Indeed, these results suggest it is unlikely that suppression of liquid mixing inside MECS will be significant for any chemical CCS solvents, as most solvents either have faster reaction kinetics than unpromoted $\mathrm{K}_{2} \mathrm{CO}_{3}$ (and so the Hatta number will be larger, and hence $M$ smaller) or else are too viscous to be used in a standard packed column (in which case the comparison is vacuous.)

\section{Shell Resistance, Specific Surface Area and Liquid Holdup}

As noted by Vericella et al., ${ }^{1}$ shell resistance is not particularly significant for this system. Taking $L=25 \mu \mathrm{m}$, and considering a PDMS shell with a $\mathrm{CO}_{2}$ permeability of 3000 barrer, ${ }^{37,38}$ then Eq. 
(20)-Eq. (23) give $\alpha=0.94$. For solvents that absorb gas more quickly, such as promoted $\mathrm{K}_{2} \mathrm{CO}_{3}$ or the physical solvent Selexol, shell resistance will be more significant.

The final factor that can affect $\Gamma$ is the relative surface area, which can be broken down into the surface area per unit volume of solvent and the liquid holdup inside the unit operation. Vericella et al. ${ }^{1}$ only considered the first factor: they assumed the surface area per unit volume of solvent in a packed column was equal to $1000 \mathrm{~m}^{2} \mathrm{~m}^{-3}$, and compared this with the much higher values for MECS. While this is a reasonable first estimate, a more rigorous approach is to use correlations for $a$. For example, in the $\mathrm{K}_{2} \mathrm{CO}_{3}$ system discussed above, the specific surface area per unit volume of absorber of Mellapak $500 \mathrm{Y}$ with a liquid flowrate of $5 \mathrm{~kg} \mathrm{~m}^{-2} \mathrm{~s}^{-1}$ is approximately $360 \mathrm{~m}^{2} \mathrm{~m}^{-3}$. If the liquid layer were $1 \mathrm{~mm}$ thick (as assumed by Vericella et al.) then, as

$$
h=\text { Liquid thickness } \times a,
$$

the liquid holdup, $h$, inside the column would be $36 \%$. Suess and Spiegel ${ }^{39}$ developed the following correlation for liquid holdup for Mellapak 500Y when $L / \rho<40 \mathrm{~m}^{3} \mathrm{~m}^{-2} \mathrm{~h}^{-1}$ :

$$
h=1.69 \times 10^{-4} a_{t}^{0.83}\left(\frac{L}{\rho} \cdot\left[\frac{\mathrm{m}^{2} \mathrm{~h}}{\mathrm{~m}^{3}}\right]\right)^{0.37}\left(\frac{\mu}{\mu_{\mathrm{water}, 20^{\circ} \mathrm{C}}}\right)^{0.25}
$$

where $L / \rho$ should be measured in $\mathrm{m}^{3} \mathrm{~m}^{-2} \mathrm{~h}^{-1}$. According to this correlation, for a liquid flow rate of $5 \mathrm{~kg} \mathrm{~m}^{-2} \mathrm{~s}^{-1}$, the holdup of $\mathrm{K}_{2} \mathrm{CO}_{3}$ solution is $8.9 \%$. Rearranging Eq. (26), the liquid film thickness will be closer to $0.25 \mathrm{~mm}$ : 4 times thinner than originally assumed. This suggests that the surface area comparison of Vericella et al. may have overemphasised the benefits MECS can provide. However, it does not invalidate their experimental approach of using a $1 \mathrm{~mm}$ thin film to simulate an absorption column. This is because, as absorption is strongly diffusion controlled in unpromoted $\mathrm{K}_{2} \mathrm{CO}_{3}$, the initial absorption rate per unit area is independent of film thickness.

In Figure 6, the increase in surface area per unit volume of absorber that MECS can provide is plotted against particle diameter for various packings, assuming various $\varepsilon$ values. The chosen voidages are typical of fluidised bed operations, ${ }^{16}$ though $\varepsilon=0.8$ is also a reasonable value for a bed of MECS supported in a porous packing. Following Vericella et al., ${ }^{1}$ the increase in area per unit volume of solvent is also plotted, assuming the liquid in the packed bed is $1 \mathrm{~mm}$ thick. The equation 
for this line is:

$$
\Lambda \equiv \frac{3 / r}{1000 \mathrm{~m}^{2} \mathrm{~m}^{-3}}
$$

The increase in surface area on a reactor-volume basis is generally smaller than $\Lambda$. Indeed, if the largest MECS particles $(r=300 \mu \mathrm{m})$ were placed in a fluidised bed with $\varepsilon=0.95$, then the surface area on a unit volume of absorber basis would be almost identical to that of a traditional absorber containing Mellapak 500Y, even though the calculation of Vericella et al. would suggest a 10-fold increase in specific surface area in this case. In general, the assumption of a $1 \mathrm{~mm}$ thin layer appears relatively optimistic, and for Mellapak 500Y it leads to an overestimation of the enhacement in surface area by a factor of 3-10. While the large surface areas inside the packed columns could in principle be due to very large liquid holdups, liquid holdups are typically $<15 \%$ for these packings, ${ }^{39,40}$ so the discrepancy is instead predominantly due to thinner than expected liquid films.

\section{Absorption Rate per Unit Volume of Absorber}

In Figure 7, all the above factors are combined to give the overall increase in specific absorption rate, $\Gamma$, as a function of MECS diameter. $\Lambda$, as defined in Eq. (28), is also plotted. The enhancement plateaus for very small particles as mass transfer becomes reaction controlled, but for the smallest MECS which are currently manufactured (with diameters of about $100 \mu \mathrm{m}$ ) mass transfer is still close to diffusion controlled ( $\phi=5.3$ in this case.) The transition to the reaction-controlled regime will be even less significant for promoted carbonate solutions or other solvents with faster reaction kinetics.

Overall, the difference between $\Gamma$ and $\Lambda$ is similar to that shown in Figure 6 , and can largely be attributed to the large liquid surface areas in packed columns. The suppression of liquid mixing and the presence of shell resistance have a relatively minor influence on the value of $\Gamma$, each affecting its value by $<10 \%$. For small MECS with diameters of $100 \mu \mathrm{m}$, the improvement microencapsulation can provide ranges from $7-60$, and the value of $\Lambda$ at this point is at the very top of this range. In general, $\Lambda$ is a relatively optimistic estimate for the enhancement in specific absorption rate MECS can provide, and it may overestimate the improvement by as much as a factor of 10 . While further work should be undertaken to design and size specific processes utilising MECS, these results suggests that, for chemically reactive solvents, the improvement in specific absorption rate may not be as significant as has been claimed to date. 


\section{Selexol for $\mathrm{CO}_{2}$ Removal}

If a gas is absorbed by a MECS particle containing a physical solvent, the flux does not asymptote to a constant expression, however the dynamics are well approximated by the linear driving force model Eq. (15). Unlike the diffusion-controlled MECS containing chemically reactive solvents discussed above, the flux into physical solvents depends on the particle radius. The flux is larger for smaller particles, as concentration gradients increase as particle size is reduced. Given that the diameters of MECS particles are typically smaller than the thicknesses of liquid films in absorption columns, this effect should lead to an increase in gas flux. On the other hand, physical solvents may also be considered the limiting case of very slow chemically reactive solvents, and it has been found that suppression of liquid mixing (and associated convective mass transfer) is particularly significant for such solvents. The relative weight of these competing factors can only be assessed on a case-by-case basis.

The absorption of $\mathrm{CO}_{2}$ from a $\mathrm{CH}_{4} / \mathrm{CO}_{2}$ mixture into MECS containing the physical solvent Selexol is analysed below; relevant material properties are summarised in Table 3. Selexol is a mixture of polyethylene glycol dimethyl ethers, which is widely used to remove acid gases from high-pressure (2-14MPa) gas streams. ${ }^{41}$ While MECS containing physical solvents such as Selexol have not yet been manufactured, there is no reason in principle why they could not be, and, just as for chemical solvents, the increase in surface area could lead to substantial reductions in unit size. MECS with shell thicknesses equal to $10 \%$ of their diameter were compared with a packed column containing metal IMTP-40, which is often used in Selexol-based acid gas treating operations. ${ }^{42}$ The correlation of Hanley and $\mathrm{Chen}^{27}$ was used to predict $k_{L}$ and $a$ : this correlation was specifically regressed using data from IMTP packings, and was in good agreement with experimental data for several physical solvent systems.

In Figure 8, values of $M$ are plotted against MECS diameter for various liquid flow rates. As opposed to chemical solvents (for which $M \geq 1$ ) the flux of gas into the smallest MECS particles containing Selexol was larger than the flux into a comparable absorption column. In this case, the reduction in particle size, with associated increase in concentration gradients, is more significant than the suppression of liquid mixing, and microencapsulation would increase both the specific surface area and the gas flux. This is in spite of the fact that, because this solvent absorbs gas quite quickly, shell resistance is particularly significant, with $\alpha \approx 0.5$ in this case. For solvents which absorb gas 
more slowly, shell resistance will be less significant, and the enhancement that microencapsulation can provide will be correspondingly greater. In Figure 9, the increase in specific absorption rate into MECS, $\Gamma$, is plotted against particle diameter for various values of $\varepsilon . \Lambda$, as defined by Eq. (28), is also plotted. It can be seen that, for the smallest MECS particles, microencapsulation would increase the specific gas absorption rate by even more than $\Lambda$ predicts, and for the smallest particles the increase would be $50-150$-fold. This is in contrast to the case of the chemically reactive $\mathrm{K}_{2} \mathrm{CO}_{3}$ solution shown in Figure 7, for which $\Lambda$ was a relatively optimistic estimate. The increase in gas flux is an improvement not accounted for in a naive surface area comparison.

To date, research into MECS has focussed on chemical solvents, however these results suggest that microencapsulation could be more effective for physical solvents, especially for the smallest MECS particles. The dual benefit of enhanced area and enhanced flux means that the specific gas absorption rate increases as $1 / r^{2}$, rather than $1 / r$. The formation of small MECS containing ionic liquids which physically absorb carbon dioxide ${ }^{45}$ should continue to be investigated.

Thoughout this analysis, it was assumed that both gas-phase resistance and internal liquid motion were insignificant; the validity of these assumptions are discussed in the following two sections.

\section{Gas-Phase Resistance}

Absorption from dilute gas streams is gas-side controlled whenever $k_{G} /\left(E H k_{L}\right) \ll 1$, and liquid-side controlled for $k_{G} /\left(E H k_{L}\right) \gg 1$, where for physical solvents the enhancement factor due to reaction, $E$, is equal to 1 , while for chemical solvents undergoing pseudo-first order reactions, Danckwerts ${ }^{12}$ predicts $E=\sqrt{1+\mathrm{Ha}^{2}}$.

Both Onda et al. ${ }^{23}$ and Shulman et al. ${ }^{21}$ developed correlations for $k_{G}$, and their predictions were in much better agreement than their $k_{L}$ correlations, only varying by $\pm 15 \%$ over the range $100<G d / \mu_{G}\left(1-\varepsilon^{\prime}\right)<10,000 .{ }^{23}$ In Table 4, values of $k_{G} /\left(E H k_{L}\right)$, calculated via the correlation of Onda et al., are listed for the various systems analysed above. In all cases considered this ratio was orders of magnitude greater than 1 , and so the assumption of liquid phase control is very reasonable in these absorption columns. This should also be the case for MECS particles, as even though gas-phase mass transfer resistance into MECS may be different to that in a column, it is unlikely to be orders of magnitude larger. 


\section{Internal Liquid mixing}

It was assumed in the analysis above that internal motion of the liquid inside MECS is not significant enough to influence the rate of gas absorption. This assumption should be valid for static MECS placed in a packed column. While it is possible for convective currents, caused by the formation of density gradients, thermal gradients, surface tension effects or solvent evaporation, to form spontaneously in static liquids during gas absorption, models based upon pure diffusion with reaction have been shown to be reasonable for many static liquids, ${ }^{5}$ and the presence of the solid MECS shell will only suppress convective motion further. On a practical level, stacking $\sim 100 \mu \mathrm{m}$ MECS directly into a packed column is infeasible, as the pressure drop would be far too large. However it may be possible to pelletize MECS inside porous supports. Such an approach could help to solve several issues related to heat recovery and solids handling, and it is a plausible pathway for the industrial application of MECS for which the analysis above is completely valid.

On the other hand, if MECS particles are fluidised, it is possible that changes in angular velocity and compression of the shells during particle collisions could lead to mixing inside the particles, and could influence the rate of mass transfer. For the case of chemically reactive solvents, it seems unlikely that mass transfer will be influenced by particle movement. It was shown above that, even for a solvent with relatively slow reaction kinetics placed inside an absorption column, liquid mixing did not significantly affect mass transfer. The Hatta number of the liquid inside a MECS particle should be larger than in an absorption column, as the capsule walls will tend to suppress liquid motion, and so $M$ would be even closer to unity in this case. This is supported by the experiments of Vericella et al., ${ }^{1}$ who fluidised MECS containing $3 \mathrm{wt} \% \mathrm{~K}_{2} \mathrm{CO}_{3}$ in a stream of $\mathrm{CO}_{2}$. The MECS contained thymol blue, so that the $\mathrm{CO}_{2}$ loading could be visualised. In videos of their experiment, some particles were heavily fluidised, while others were immobile, clumped together at the top or bottom of the column. However, all particles changed colour at the same rate, independent of the degree of particle motion.

In order to investigate the effect of larger particle strains on gas uptake rate, $500 \mu \mathrm{m}$ MECS containing $3 \mathrm{wt} \% \mathrm{~K}_{2} \mathrm{CO}_{3}$ and thymol blue, supplied by Lawrence Livermore National Laboratory, were analysed in the apparatus shown in Figure 10. A number of MECS were placed inside region A where they could be compressed by manually moving the right glass rod. Several more MECS were placed in region $\mathrm{B}$, where they would not undergo any compression. The entire junction was flooded with $\mathrm{CO}_{2}$, and the MECS particles in region A were manually compressed at $\sim 2.5 \mathrm{~Hz}$ with Cauchy 
strains between $30-80 \%$ until $\mathrm{CO}_{2}$ absorption was complete. As shown in Figure 11, the rate of colour change was identical for particles in region $\mathrm{A}$ and region $\mathrm{B}$, indicating that even extremely large particle strains would not affect the rate of mass transfer into even a relatively slow, non-viscous chemically reactive solvent. For more viscous solvents, or solvents with faster chemical kinetics, liquid mixing should be even less significant.

While it seems likely that MECS motion will not influence gas absorption in particles containing chemically reactive solvents, it is unclear if this would also be true for MECS containing physical solvents, for which liquid mixing is typically a more significant factor. No experimental data analagous to that above is available for this case. Below we present the results of some preliminary calculations.

Liquid mixing inside a spherical MECS particle can be induced by changes in the angular velocity and by particle compression during collisions. In order to investigate the former, a 3D, dynamic model of a spherical ball of liquid was created using the simulation software arb. ${ }^{46}$ The model simultaneously solved the Navier-Stokes equations and the convection-diffusion-reaction equation, and was used to study how changes in the angular velocity of the surface of the liquid (analagous to changes in the angular velocity of a rigid MECS shell during a collision) influenced liquid flows inside the particle and the rate of gas absorption. Both pure diffusion and diffusion with first order chemical reaction were studied over $10^{-1}<\operatorname{Re}<10,1<\phi<10^{2}$ (for the chemical system) and $10<r^{2} \omega / \mathscr{D}<10^{3}$ (this last dimensionless parameter represents the relative timescales for the mass transfer and momentum transfer problems.) When the angular velocity of the shell was regularly changed, complex flow patterns developed inside the fluid. However, in all cases tested, the radial component of the velocity was negligible (at least 3 orders of magnitude less than $\omega r$ ), and for both physical and chemical solvents, shell rotation had no measurable effect on the rate of gas absorption.

Particle compression could also cause liquid motion inside MECS. By extending the linear elastic theory of Hertz ${ }^{47}$ and Reissner, ${ }^{48}$ Berry et al. ${ }^{49}$ derived the following equation, valid for $0<z / R \leq 1$, for the force with which a hollow elastic shell will resist deformation:

$$
\frac{F \sqrt{3\left(1-v^{2}\right)}}{(z / R)^{3} 4 R^{2}}=\mathscr{E} \beta_{1}\left(\frac{C \delta}{z}\right)^{\beta_{2}}
$$

Here $z$ is the shell thickness, $\delta$ the shell deformation, and $R$ the particle radius. The linear elastic theory gives reasonable predictions until buckling occurs at approximately $\delta / z=3,{ }^{50}$ however, as Eq. (29) does not account for the presence of the viscous liquid inside the capsules, particle compression 
will be overestimated. $\beta_{1}$ and $\beta_{2}$ are constants that depend on $z / R$, while, following Reissner, ${ }^{48} C=1$ for the single-sided compression which occurs when a MECS particle collides with a wall or another particle. By integrating Newton's second law with the force term given by Eq. (29), the maximum particle deformation, $\delta_{\max }$, can be calculated as a function of $z / R$ and the initial particle velocity, $v_{0}$. The results are shown in Figure 12, in which $\delta_{\max } / D$ is plotted against $v_{0}$.

Meissner and Kusik ${ }^{51}$ showed that in a fluidised bed containing $200 \mu \mathrm{m}$ particles of sand, particle velocities were comparable to the gas superficial velocity. The correlation of Wen and $\mathrm{Yu}^{52}$ predicts that minimimum fluidisation of $100-500 \mu \mathrm{m}$ particles with $\rho=1300 \mathrm{~kg} \mathrm{~m}^{-3}$ will occur at gas velocities of $0.5-10 \mathrm{~cm} \mathrm{~s}^{-1}$, and the phase diagram of Grace ${ }^{53}$ predicts that for these particles the bubbling fluidisation regime will persist for gas velocities 1-2 orders of magnitude larger than minimum fluidisation, with the onset of turbulent fluidisation above that. These results suggest that particle velocities in fluidised beds containing MECS are likely to be on the order of magnitude of $1 \mathrm{~m} \mathrm{~s}^{-1}$, and possibly even larger for vigorous fluidisation of bigger MECS particles.

Despite the large gas velocities, the strains shown in Figure 12 are significantly less than those experienced by the MECS which were compressed in the experiment above, and it is still expected that, for chemically reactive solvents, compressions should not influence the gas flux. For physical solvents, on the other hand, it is difficult to make any absolute conclusions. It is plausible that regular, sudden strains of 10-20\% coupled with instantaneous changes in particle angular velocity could lead to significant liquid motion which could enhance mass transfer. Further experimental or modelling work is required to determine if the flux may be affected by liquid motion in this case.

\section{Discussion}

By comparing the predictions of models of absorption into packed colums and into MECS, it has been found that microencapsulation can provide a 1-2 orders of magnitude increase in the gas absorption rate per unit volume of absorber. However, the analysis also suggests that previous publications have underestimated the surface area available for mass transfer in structured packings such as Mellapak 500Y, and so have overestimated the potential increase in surface area that MECS can provide.

The example systems discussed above can be used to make some quite general statements about microencapsulated solvents. $30 \mathrm{wt} \% \mathrm{~K}_{2} \mathrm{CO}_{3}$ has relatively slow reaction kinetics, and so convective transport of gas molecules is likely to be particularly significant. However, when appropriate $k_{L}$ 
and $a$ correlations were selected, it was found that even for this system the absorption rate was not affected by surface renewal. For chemical solvents with faster chemical kinetics, the suppression of liquid mixing inside MECS will be even less significant. Similarly, for this slow chemical system, reaction control was not a significant factor even for the smallest MECS, and the relaxation time, $\min \left(r^{2} / \mathscr{D}, k^{-1}\right)$, for the asymptotic flux Eq. (1) to be valid was less than $0.1 \mathrm{~s}$. For solvents with faster reaction kinetics, the assumption of diffusion control and the validity of asymptotic flux expressions such as (1) will be even more reasonable.

For physical solvents, a fundamental analysis revealed some particularly interesting behaviour. In this case, the flux into MECS is strongly dependent on the particle diameter, with smaller particles absorbing gas more quickly. In the particular example discussed above, for small particles microencapsulation led to an increase in gas flux compared to the flux in an absorption column, even when the reduction in flux of $\sim 50 \%$ due to the shell was accounted for. On the other hand, for larger particles the improvement in absorption rate drops very quickly. Any technological breakthroughs which could lead to smaller MECS particles will be particularly powerful in this case, as there is no possibility of a transition to a reaction controlled regime, and (ignoring shell resistance effects) the specific absorption rate will scale with $1 / r^{2}$. Experimental work is required to confirm that the linear driving force model is reasonable in this case, and to quantify the effect of particle motion on fluidised MECS.

The ultimate goal for microencapsulation is that the kinetic enhancements discussed in this paper be translated into thermodynamic enhancements, as the technology enables slower, more efficient solvents to be used in a practical way. However, at present, the thermodynamic improvements that are possible with this technology have not been thoroughly analysed. Of course, this is a very difficult problem: the thermodynamic properties of chemical solvents cannot be easily summarised by quantities like heat of absorption ${ }^{54}$ or water content, ${ }^{55}$ but can only be evaluated by looking at the details of particular process designs. Nevertheless, it is clear that fundamental, diffusion-with-reaction based models of MECS can be used to predict their behaviour, and so widely available data on the thermodynamic properties, $\mathrm{CO}_{2}$ diffusivity and reaction rates inside liquid solvents could be used to put bounds on the possible range of MECS performance. At the very least it should be possible to compare the thermodynamic and kinetic properties of MECS with comparable solid adsorbent materials.

Focusing on the kinetic enhancement MECS can provide may also obscure some unresolved design issues. Management of water inside MECS is a potential issue, especially for smaller particles. 


\section{Conclusion}

A careful comparison of MECS and traditional packed columns provides some insight into the differences between the two technologies. Modern structured packings have extremely high surface areas, and correlations for effective area predict that microencapsulation may not increase the specific surface area on a unit volume of absorber basis by as much as has been previously suggested. On the 
other hand, $k_{L}$ correlations suggest that the flux into MECS containing chemical solvents will not be substantially reduced by the suppression of liquid mixing inside the capsules. Furthermore, for physical solvents, for which the relevant spatial scale is the thickness of the fluid, it is possible that microencapsulation may increase both the surface area and the gas flux. CFD simulations revealed that changes in the angular momentum of the particle shells will not significantly affect mass transfer rates. However, vigorously fluidised particles could be expected to undergo strains as large as $10-20 \%$ during a collision, and this could induce irregular liquid mixing. Experiments on a chemical solvent with relatively slow reaction kinetics, $30 \mathrm{wt} \% \mathrm{~K}_{2} \mathrm{CO}_{3}$, revealed that even under much larger strains, mass transfer rates are unaffected by particle motion. This should also remain true for solvents with faster kinetics operating with larger Hatta numbers. On the other hand, it is unclear at present whether particle collisions will affect mass transfer into MECS containing physical solvents, and this case should be investigated further.

This study is a high-level comparison of MECS and absorption columns, and does not account for several important factors, including water loss, heat recovery, and losses associated with backmixing of solids in fluidised beds. Future work should focus on these critical issues, which can only be addressed through the design and accurate modelling of specific processes utilising microencapsulated sorbents.

\section{Notation}

- $a$ - Effective area in absorption column on unit volume of absorber basis, $\mathrm{m}^{2} \mathrm{~m}^{-3}$ absorber.

- $a^{\prime}$ - Effective area in absorption column on unit volume of solvent basis, $\mathrm{m}^{2} \mathrm{~m}^{-3}$ solvent.

- $a_{\mathrm{MECS}}$ - Specific surface area of MECS on unit volume of absorber basis, $\mathrm{m}^{2} \mathrm{~m}^{-3}$ absorber.

- $a_{\text {MECS }}^{\prime}$ - Specific surface area of MECS on unit volume of solvent basis, $\mathrm{m}^{2} \mathrm{~m}^{-3}$ solvent.

- $a_{t}$ - Total packing area, $\mathrm{m}^{2} \mathrm{~m}^{-3}$ absorber.

- $a_{w}$ - Wetted packing area, $\mathrm{m}^{2} \mathrm{~m}^{-3}$ absorber.

- $\bar{c}$ - Physical gas concentration in bulk of chemically reactive solvent, $\mathrm{mol} \mathrm{m}^{-3}$

- $c^{*} \equiv H p_{\mathrm{CO}_{2}}$ - Physical gas concentration in liquid at equilibrium with gas, $\mathrm{mol} \mathrm{m}^{-3}$ 
- $c_{\mathrm{av}}$ - Average physical gas concentration in physical solvent, $\mathrm{mol} \mathrm{m}^{-3}$

- $c_{\text {bulk }}$ - Physical gas concentration in bulk of physical solvent, $\mathrm{mol} \mathrm{m}^{-3}$

- $c_{i}$-Physical gas concentration at liquid surface; for MECS, this is the concentration at the liquid surface inside the polymer shell, $\mathrm{mol} \mathrm{m}^{-3}$

- $C$ - Dimensionless constant in Eq. (29)

- $\Delta c$ - Difference in physical gas concentration between liquid surface and liquid bulk, $\mathrm{mol} \mathrm{m}^{-3}$

- $D$ - MECS diameter, $\mathrm{m}$

- $\mathscr{D}$ - Gas diffusivity, $\mathrm{m} \mathrm{s}^{-2}$

- $d_{h} \equiv 4 \varepsilon / a_{t}$ - Hydaulic diameter of packing, m

- $d_{p}$ - Nominal diameter of packing (i.e. $0.0254 \mathrm{~m}$ for $1 / 2$-inch Raschig Rings), $\mathrm{m}$

- $d_{s}$ - Diameter of sphere with same surface area as packing, $\mathrm{m}$

- $E$ - Enhancement in flux provided by chemical reaction

- $F$ - Force required to compress thin-walled capsule, $\mathrm{N}$

- Fr - Froude Number

- $F_{S E}$ - Surface enhancement factor

- $g$ - Gravitational constant, $\mathrm{m} \mathrm{s}^{-2}$

- $G$ - Gas flow rate, $\mathrm{kg} \mathrm{m}^{-2} \mathrm{~s}^{-1}$

- $H$ - Henry's constant, $\mathrm{mol} \mathrm{Pa}{ }^{-1} \mathrm{~m}^{-3}$

- Ha - Hatta number

- $h$ - Liquid holdup, $\mathrm{m}^{3}$ liquid $\mathrm{m}^{-3}$ absorber

- $J$ - Flux into liquid, mol $\mathrm{m}^{-2} \mathrm{~s}^{-1}$

- $J_{\text {MECS }}$ - Flux into MECS, mol m${ }^{-2} \mathrm{~s}^{-1}$ 
- $J_{\text {Column }}$ - Flux into liquid in packed column mol m${ }^{-2} \mathrm{~s}^{-1}$

- $j_{D}$ - Mass transfer factor

- $k$ - Pseudo-first order chemical reaction rate constant, $\mathrm{s}^{-1}$

- $k_{L}$ - Liquid phase mass transfer coefficient, $\mathrm{m} \mathrm{s}^{-1}$

- $k_{G}$ - Gas phase mass transfer coefficient, $\mathrm{mol} \mathrm{s}^{-1} \mathrm{~m}^{-2} \mathrm{~Pa}^{-1}$

- $k_{\mathrm{LDF}}$ - Linear driving force constant, $\mathrm{m} \mathrm{s}^{-1}$

- $L$ - Liquid flow rate, $\mathrm{kg} \mathrm{m}^{-2} \mathrm{~s}^{-1}$

- $L_{p}$ - Wetted perimeter of packing, $m$

- $M$ - Ratio of gas flux in packed column to gas flux in MECS

- $M_{M}$ - Molar mass, $\mathrm{kg} \mathrm{mol}^{-1}$.

- $P_{B M}$ - Log mean partial pressure of inert gas, $\mathrm{Pa}$

- $p_{\mathrm{CO}_{2}}-\mathrm{CO}_{2}$ partial pressure, $\mathrm{Pa}$

- $p_{i}^{\text {bulk }}$ - Partial pressure of species $i$ in bulk, $\mathrm{Pa}$

- $p_{i}^{*}$ - Partial pressure of species $i$ at gas-liquid interface, $\mathrm{Pa}$

- $\mathscr{P}_{\text {shell }}$ - Permeability of MECS shell to gas, mol s ${ }^{-1} \mathrm{~m}^{-1} \mathrm{~Pa}^{-1}$

- $q_{i}$ - Packing-dependent constant in correlation

- $r$ - Radius of liquid sphere inside MECS particle, $\mathrm{m}$

- $R$ - Radius of capsule (including wall thickness), $\mathrm{m}$

- $\bar{R}_{\text {Column }}$ - Rate of absorption of gas in absorber per unit volume of absorber, $\mathrm{mol} \mathrm{s}^{-1} \mathrm{~m}^{-3} \mathrm{ab}-$ sorber.

- $\bar{R}_{\text {MECS }}$ - Rate of absorption of gas into MECS per unit volume of absorber, $\mathrm{mol} \mathrm{s}^{-1} \mathrm{~m}^{-3} \mathrm{ab}-$ sorber.

- Re - Reynolds number, defined as $\rho \omega r^{2} / \mu$ for spinning MECS particle.

This article is protected by copyright. All rights reserved. 
- $\mathscr{R}$ - Resistance to mass transfer, $\mathrm{s} \mathrm{m}^{-1}$

- $v_{0}$ - MECS velocity prior to collision, $\mathrm{m} \mathrm{s}^{-1}$

- We - Weber number

- $z$ - Shell thickness, m

\section{Greek Letters}

- $\alpha=\left(c_{i}-\bar{c}\right) / \Delta c$ - Fractional reduction in flux due to shell resistance in chemical solvent.

- $\alpha^{\prime}=\left(c_{i}-c_{\mathrm{av}}\right) / \Delta c$ - Fractional reduction in flux due to shell resistance in physical solvent.

- $\beta_{i}$ - Dimensionless constants in Eq. (29).

- $\delta$ - Compression of MECS particle, $\mathrm{m}$

- $\varepsilon$ - Unit operation voidage, $\mathrm{m}^{3}$ liquid-free space $\mathrm{m}^{-3}$ absorber

- $\mathscr{E}$ - Young's Modulus, Pa

- $\Gamma$ - Ratio of specific absorption rate into MECS to specific absorption rate in an absorption column, on a unit volume of absorber basis.

- $\Lambda$ - Increase in surface area per unit volume of solvent, compared with a $1 \mathrm{~mm}$ layer of liquid.

- $\phi \equiv \sqrt{k r^{2} / \mathscr{D}}$ - Thiele modulus.

- $\mu$ - Viscosity, Pa s

- $\rho$ - Density, $\mathrm{kg} \mathrm{m}^{-3}$

- $\sigma$ - Surface tension, $\mathrm{N} \mathrm{m}^{-1}$

- $\sigma_{c}$ - Critical surface tension of packing, $\mathrm{N} \mathrm{m}^{-1}$

- $v$ - Poisson's ratio

- $\omega$ - Angular velocity of spinning MECS, $\mathrm{s}^{-1}$ 


\section{Literature Cited}

${ }^{1}$ Vericella JJ, Baker SE, Stolaroff JK, Duoss EB, Hardin JO, Lewicki J, Glogowski E, Floyd WC, Valdez CA, Smith WL, Satcher JH, Bourcier WL, Spadaccini CM, Lewis JA, Aines RD. Encapsulated liquid sorbents for carbon dioxide capture. Nature Communications. 2015;6(6124).

${ }^{2}$ Smith K, Lee A, Mumford KW, Li S, Indrawan, Thanumurthy N, Temple N, Anderson C, Hooper B, Kentish S, Stevens GW. Pilot plant results for a precipitating potassium carbonate solvent absorption process promoted with glycine for enhanced $\mathrm{CO} 2$ capture. Fuel Processing Technology. 2015;135:60-65.

${ }^{3}$ Seo S, Simoni LD, Ma M, DeSilva MA, Huang Y, Stadtherr MA, Brennecke JF. Phase-Change Ionic Liquids for Postcombustion CO2 Capture. Energy Fuels. 2014;28(9):5968-5977.

${ }^{4}$ Stolaroff JK, Ye C, Oakdale JS, Baker SE, Smith WL, Nguyen DT, Spadaccini CM, Aines RD. Microencapsulation of advanced solvents for carbon capture. Faraday Discussions. 2016;192:271281.

${ }^{5}$ Danckwerts PV. Gas-Liquid Reactions. McGraw-Hill. 1970.

${ }^{6}$ Aines RD, Spaddaccini CM, Duoss EB, Stolaroff JK, Vericella J, Lewis JA, Farthing G. Encapsulated Solvents for Carbon Dioxide Capture. Energy Procedia. 2013;37:219-224.

${ }^{7}$ Levenspiel O. Chemical Reaction Engineering. Wiley, 3rd ed. 1999.

${ }^{8}$ Raksajati A, Ho M, Wiley DE. Techno-economic Evaluation of CO2 Capture from Flue Gases Using Encapsulated Solvent. Industrial and Engineering Chemistry Research. 2017;56(6):16041620.

${ }^{9}$ Stolaroff JK, Ye C, Nguyen DT, Oakdale J, Knipe JM, Baker SE. CO2 absorption kinetics of micro-encapsulated ionic liquids. Energy Procedia. 2017;113:860-865.

${ }^{10}$ Bird RB, Stewart WE, Lightfoot EN. Transport Phenomena. John Wiley and Sons, 2nd ed. 2006.

${ }^{11}$ Haroun Y, Raynal L. Use of Computational Fluid Dynamics for Absorption Packed Column Design. Oil and Gas Science and Technology. 2016;71(3). 
${ }^{12}$ Danckwerts PV. Significance of Liquid-Film Coefficients in Gas Absorption. Industrial and Engineering Chemistry. 1951;43(6):1460-1467.

${ }^{13}$ Higbie R. The Rate of Absorption of a Pure Gas into a Still Liquid during Short Periods of Exposure. AiChE Journal. 1935;31:365-389.

${ }^{14}$ Whitman WG. The Two-Film Theory of Gas Absorption. Chemical and Metalurgical Engineering. 1923;29(4):146-148.

${ }^{15}$ Ruthven DM. Principles of Adsorption and Adsorption Processes. Wiley-Interscience. 1984.

${ }^{16}$ Kunii D, Levenspiel O. Fluidization Engineering. Butterworth-Heinemann, 2nd ed. 1991.

${ }^{17}$ Glueckauf E. Theory of chromatography. Part 10. - Formulæ for diffusion into spheres and their application to chromatography. Transactions of the Faraday Society. 1955;51:1540-1551.

${ }^{18}$ Sircar S, Hufton J. Why Does the Linear Driving Force Model for Adsorption Kinetics Work? Adsorption. 2000;6(2):137-147.

${ }^{19}$ Wang GQ, Yuan XG, Yu KT. Review of Mass Transfer Correlations for Packed Columns. Industrial and Engineering Chemistry Research. 2005;44(23):8715-8729.

${ }^{20}$ Hegely L, Roesler J, Alix P, Rouzineau D, Meyer M. Absorption methods for the determination of mass transfer parameters of packing internals: A literature review. AIChE Journal. 2017; 63(8):3246-3275.

${ }^{21}$ Shulman HL, Ullrich CF, Proulx AZ, Zimmerman JO. Performance of packed columns. II. Wetted and effective-interfacial areas, gas- and liquid-phase mass transfer rates. AIChE Journal. 1955; $1(2): 253-258$.

22 Treybal RE. Mass-Transfer Operations. McGraw Hill, 3rd ed. 1980.

${ }^{23}$ Onda K, Takeuchi H, Okumoto Y. Mass Transfer Coefficients Between Gas and Liquid Phases in Packed Columns. Journal of Chemical Engineering of Japan. 1968;1(1):56-62.

${ }^{24}$ Staudinger J, Knocke WR, Randall CW. Evaluating the Onda Mass Transfer Correlation for the Design of Packed-Column Air Stripping. Journal of the American Water Works Association. 1990; 82(1):73-79. 
${ }^{25}$ Mumford KA, Smith K, Anderson C, Shen S, Tao W, Suryaputradinata Y, Qader A, Hooper B, Innocenzi R, Kentish SE, Stevens GW. Post-combustion capture of CO2: results from the solvent absorption capture plant at Hazelwood power station using potassium carbonate solvent. Energy and Fuels. 2012;26:138-146.

${ }^{26}$ Fair JR, Steinmeyer DE, Penney WR, Crocker BB. Chemical Engineers' Handbook. McGraw-Hill. 1997.

${ }^{27}$ Hanley B, Chen CC. New Mass-Transfer Correlations for Packed Towers. AIChE Journal. 2012; 58(1):132-152.

${ }^{28}$ Rocha JA, Bravo JL, Fair JR. Distillation columns containing structured packings: a comprehensive model for their performance. 2. Mass-transfer model. Industrial and Engineering Chemistry Research. 1996;35(5):1660-1667.

${ }^{29}$ Billet R, Shultes M. Predicting Mass Transfer in Packed Columns. Chemical Engineering Technology. 1993;16:1-9.

${ }^{30}$ Tsai RE, Seibert AF, Eldridge RB, Rochelle GT. A Dimensionless Model for Predicting the MassTransfer Area of Structured Packing. AIChE Journal. 2011;57(5):1173-1184.

${ }^{31}$ Sohnel P, Novotny O. Densities of Aqueous Solutions of Inorganic Substances. Elsevier. 1985.

${ }^{32}$ Correia RJ, Kestin J, Khalifa HE. Viscosity and density of aqueous sodium carbonate and potassium carbonate solutions in the temperature range 20-90C and the pressure range 0-30 MPa. Journal of Chemical and Engineering Data. 1980;25(3):201-206.

${ }^{33}$ Versteeg GF, Van Swaaij WPM. Solubility and diffusivity of acid gases (carbon dioxide, nitrous oxide) in aqueous alkanolamine solutions. Journal of Chemical Engineering Data. 1988;33(1):29_ 34.

${ }^{34}$ Wilcox J, Rochana P, Kirchofer A, Glatz G, He J. Revisiting film theory to consider approaches for enhanced solvent-process design for carbon capture. Energy and Environmental Science. 2014; 7(7):1769-1785.

35 Astarita G. Gas Treating with Chemical Solvents. John Wiley. 1983. 
${ }^{36}$ Danckwerts PV, Sharma MM. Absorption of carbon dioxide into solutions of alkalis and amines (with some notes on hydrogen sulphide and carbonyl sulphide). Chemical Engineer. 1966;10:244280

${ }^{37}$ Merkel TC, Bondar VI, Freeman BD, Pinnau I. Gas sorption, diffusion, and permeation in poly(dimethylsiloxane). Journal of Polymer Science Part B: Polymer Physics. 2000;38(3):415434.

${ }^{38}$ Scholes CA, WStevens G, Kentish SE. The effect of hydrogen sulfide, carbon monoxide and water on the performance of a PDMS membrane in carbon dioxide/nitrogen separation. Journal of Membrane Science. 2010;350(1-2):189-199.

${ }^{39}$ Suess P, Spiegel L. Hold-up of Mellapak structured packings. Chemical Engineering and Processing: Process Intensification. 1992;31(2):119-124.

${ }^{40}$ Shulman HL, Ullrich CF, Wells N. Performance of packed columns. I. Total, static, and operating holdups. AIChE Journal. 1955;1(2):247-253.

${ }^{41}$ Kohl AL, Nielsen RB. Gas Purification. Gulf Professional Publishing, 5th ed. 1997.

${ }^{42}$ Koch-Glitsch. Acid gas removal and gas sweetening. 2017. Last accessed 17 November, 2017.

URL http://www.koch-glitsch.com/masstransfer/pages/acid-gasremoval-sweetening.aspx

${ }^{43}$ Li J, Mundhwa M, Henni A. Volumetric properties, viscosities, refractive indices, and surface tensions for aqueous Genosorb 1753 solutions. Journal of chemical and engineering data. 2007; 52(3):955-958.

${ }^{44}$ Poling BE, Prausnitz JM, O’Connell J. The Properties of Gases and Liquids. McGraw-Hill, 5th ed. 2000.

${ }^{45}$ Kim YS, Choi WY, Jang JH, Yoo KP, Lee CS. Solubility measurement and prediction of carbon dioxide in ionic liquids. Fluid Phase Equilibria. 2005;228-229:439-445.

${ }^{46}$ Harvie DJE. An implicit finite volume method for arbitrary transport equations. ANZIAM Journal. 2012;52:1126-1145. 
${ }^{47}$ Hertz HR. Ueber die Beruhrung fester elastischer Korper. Joural fur die Reine und Angewandte Mathematik. 1882;92:156-171.

${ }^{48}$ Reissner E. Stresses and Small Displacements of Shallow Spherical Shells. II. Studies in Applied Mathematics. 1947;27(1-4):279-300.

${ }^{49}$ Berry JD, Mettu S, Dagastine RR. Precise measurements of capsule mechanical properties using indentation. Soft Matter. 2017;13(10):1943-1947.

${ }^{50}$ Shorter R, Smith JD, Coveney VA, Busfield JJC. Axial compression of hollow elastic spheres. Journal of Mechanics of Materials and Structures. 2010;5(5):693-705.

${ }^{51}$ Meissner HP, Kusik CL. Particle velocities in a gas fluidized bed. Canadian Journal of Chemical Engineering. 1970;48(4):349-355.

${ }^{52}$ Wen CY, Yu YH. A generalized method for predicting the minimum fluidization velocity. AIChE Journal. 1966;12(3):610-612.

${ }^{53}$ Grace JR. Contacting modes and behaviour classification of gas-solid and other two-phase suspensions. The Canadian Journal of Chemical Engineering. 1986;64:353-363.

${ }^{54}$ Oexmann J, Kather A. Minimising the regeneration heat duty of post-combustion CO2 capture by wet chemical absorption: the misguided focus on low heat of absorption solvents. International Journal of Greenhouse Gas Control. 2010;4(1):36-43.

${ }^{55}$ Heldebrant DJ, Koech PK, Glezakou VA, Rousseau R, Malhotra D, Cantu DC. Water-Lean Solvents for Post-Combustion CO2 Capture: Fundamentals, Uncertainties, Opportunities, and Outlook. Chemical Reviews. 2017;117(14):9594-9624.

${ }^{56}$ Smit B, Reimer J, Oldenburg C, Bourg I. Introduction to Carbon Capture and Sequestration. Imperial College Press. 2014.

${ }^{57}$ Levenspiel O. G/S reactor models - packed beds, bubbling fluidized beds, turbulent fluidized beds and circulating (fast) fluidized beds. Powder Technology. 2002;122(1):1-9. 


\section{List of Figure Captions}

1. Typical concentration profile inside a microencapsulated solvent.

2. Comparison of the surface renewal theories of Whitman, ${ }^{14}$ Higbie $^{13}$ and Danckwerts ${ }^{12}$ for the case of absorption with pseudo-first order reaction.

3. The influence of particle size, as quantified by the Thiele Modulus, on the specific absorption rate.

4. Values of $a, k_{L}, k_{L} a$ and $\alpha M$ for $30 \mathrm{wt} \% \mathrm{~K}_{2} \mathrm{CO}_{3}$ flowing down a packed column containing 1/2-inch Raschig Rings, as predicted by the correlations of Shulman et al., ${ }^{21}$ Onda et al. ${ }^{23}$ and Billet and Shultes. ${ }^{29}$

5. Values of $a, k_{L}, k_{L} a$ and $\alpha M$ for $30 \mathrm{wt} \% \mathrm{~K}_{2} \mathrm{CO}_{3}$ flowing down a packed column containing the structured packing Mellapak 500Y, as predicted by the correlations of Rocha et al., ${ }^{28}$ Hanley and $\mathrm{Chen}^{27}$ and Tsai et al. ${ }^{30}$ Note that Tsai et al. only provides a prediction for $a$, so values of $k_{L}$ and $\alpha M$ were calculated based on the average of the $k_{L} a$ predictions of Rocha et al. and Hanley and Chen.

6. The increase in surface area on a unit volume of absorber basis which MECS can provide relative to a packed column, $a_{\mathrm{MECS}} / a$, plotted against particle diameter for various packing types. Also plotted is the increase in surface area per unit volume of solvent assuming a $1 \mathrm{~mm}$ thin layer of liquid in the packed column, $a_{\text {MECS }}^{\prime} / 1000 \mathrm{~m}^{2} \mathrm{~m}^{-3}$. M500Y: Mellapak 500Y. Raschig: 1/2 Inch Raschig Rings. $\varepsilon$ : voidage inside absorber containing MECS particles. Operating Conditions: $30 \mathrm{wt} \% \mathrm{~K}_{2} \mathrm{CO}_{3}$ flowing at $5 \mathrm{~kg} \mathrm{~m}^{-2} \mathrm{~s}^{-1}$.

7. $\Gamma$ vs particle diameter for various packing types and values of $\varepsilon$. Also plotted is the increase in surface area per unit volume of solvent assuming a $1 \mathrm{~mm}$ thin layer of liquid in the packed column, $a_{\text {MECS }}^{\prime} / 1000 \mathrm{~m}^{2} \mathrm{~m}^{-3}$. M500Y: Mellapak 500Y. Raschig: 1/2 Inch Raschig Rings. $\varepsilon$ : voidage inside absorber containing MECS particles. Operating Conditions: $30 \mathrm{wt} \% \mathrm{~K}_{2} \mathrm{CO}_{3}$ flowing at $5 \mathrm{~kg} \mathrm{~m}^{-2} \mathrm{~s}^{-1}$.

8. $M$ values for $\mathrm{CO}_{2}$ absorption into Selexol solvent as a function of particle radius, for various liquid flow rates, $L$, in the absorption column. Steel IMTP-40 packings are used. To maintain 
consistency with the chemical solvent case, a decrease in $M$ is associated with an increase in flux into the MECS particles, see Eq. (16).

9. $\Gamma$ values for $\mathrm{CO}_{2}$ absorption into Selexol solvent as a function of particle radius, for various column voidages, $\varepsilon$, assuming $L=5 \mathrm{~kg} \mathrm{~m}^{-2}$. Steel IMTP-40 packings are used.

10. Testing the effect of particle compression on gas absorption. Particles in region A are crushed as the right piston is manually moved, while particles in region B are not compressed. Both regions are exposed to identical $\mathrm{CO}_{2}$ partial pressures, and gas uptake is monitored by observing particle colour change.

11. MECS particles changing colour as they absorb $\mathrm{CO}_{2}$. The rate of colour change is identical for particles manually compressed between two glass plates (left) and uncompressed particles placed in the same gas environment. Compression frequency $\approx 2.5 \mathrm{~Hz}$, compressive strain $\approx 30-80 \%$.

12. Maximum deformation of MECS particles during a collision with a wall, as a function of relative shell thickness, $z / D$, and particle velocity before the collision, $v_{0}$.

\section{List of Table Captions}

1. General-purpose correlations for the liquid-phase mass transfer coefficient and effective masstransfer area.

2. Physical Properties of $30 \mathrm{wt} \% \mathrm{~K}_{2} \mathrm{CO}_{3}$ solution at $313 \mathrm{~K}$.

3. Physical Properties of Selexol at $30^{\circ} \mathrm{C}$.

4. Values of $k_{G} /\left(E H k_{L}\right)$ for various solvent systems. 


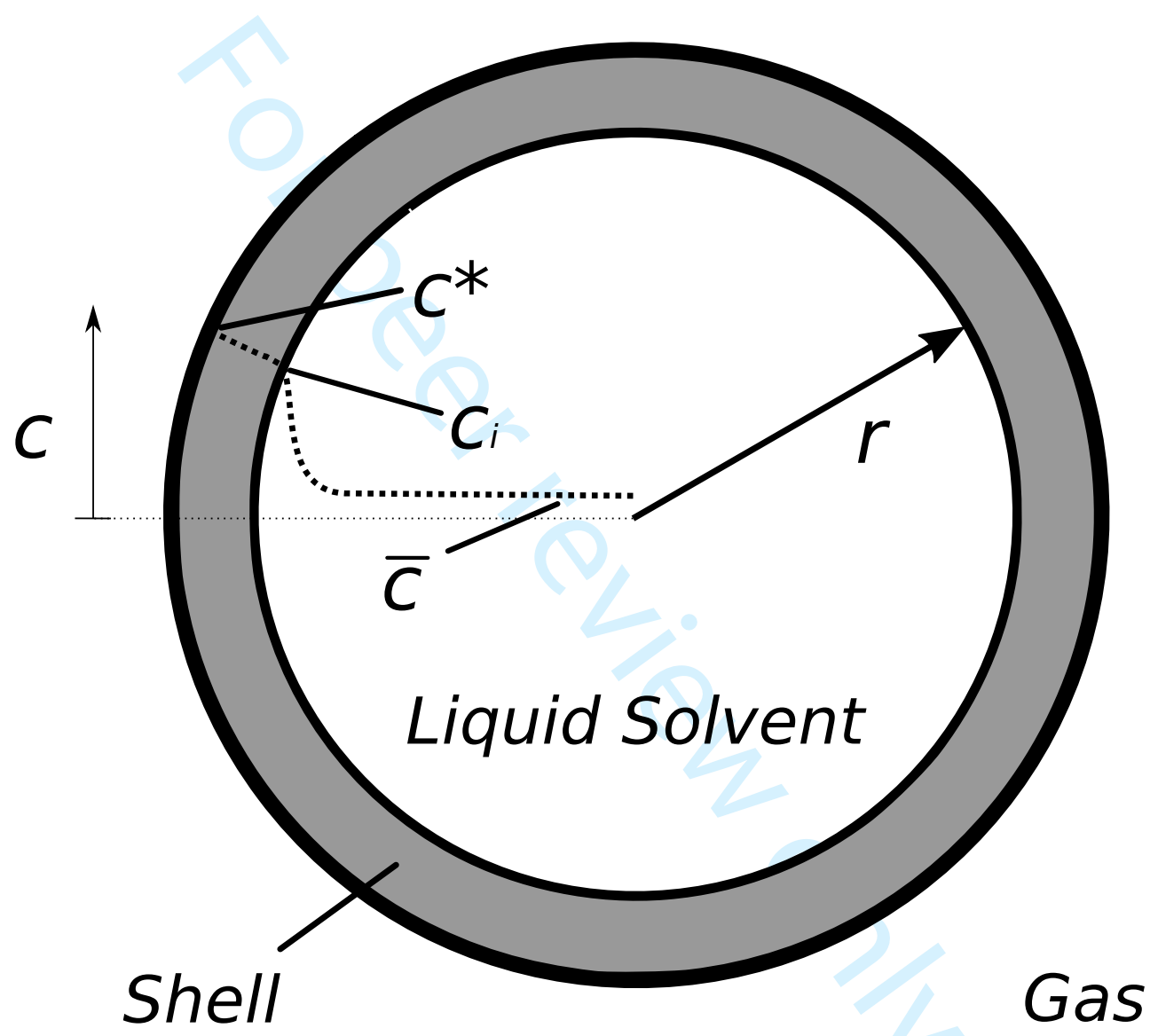

Figure 1: Typical concentration profile inside a microencapsulated solvent. 


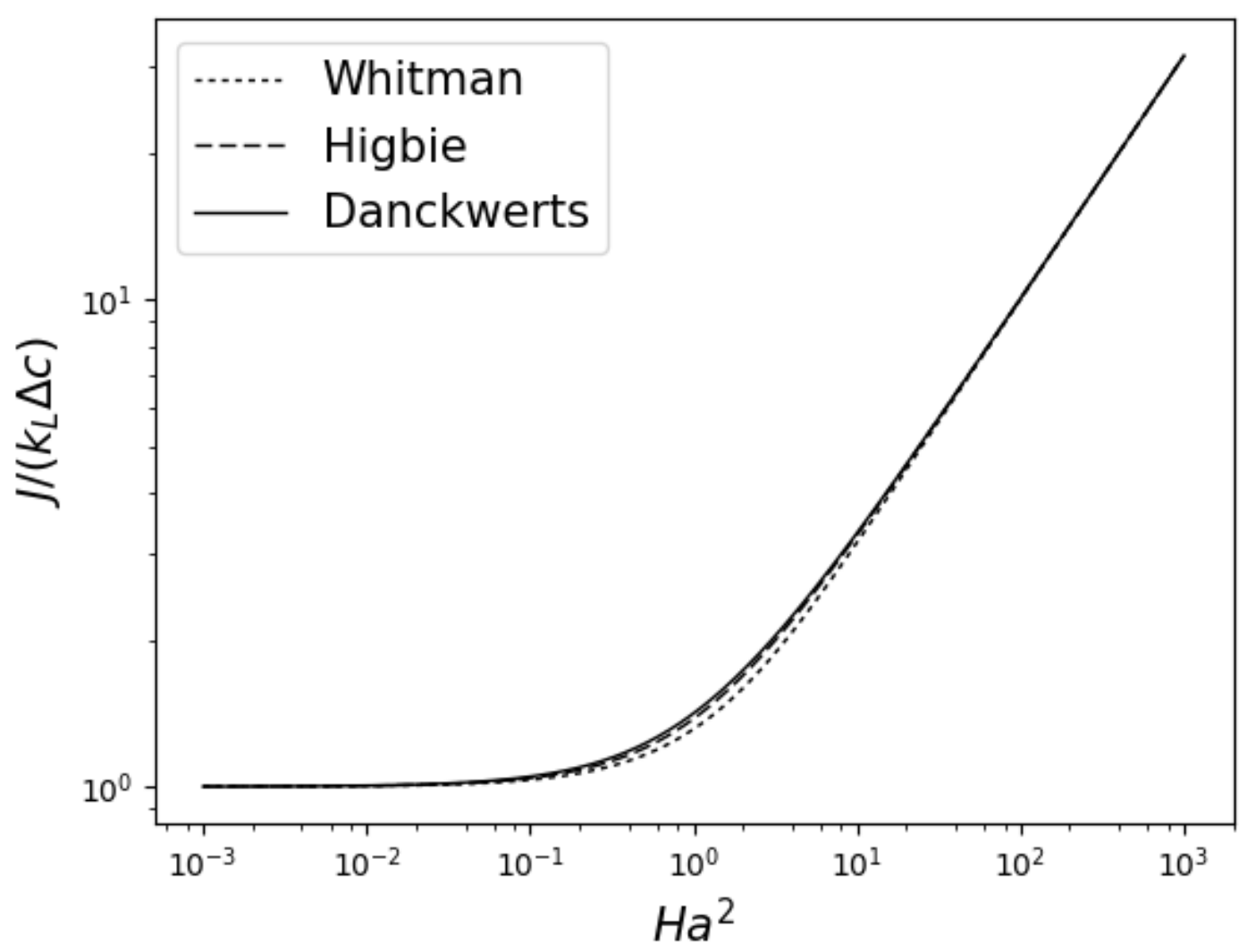

Figure 2: Comparison of the surface renewal theories of Whitman, ${ }^{14}$ Higbie $^{13}$ and Danckwerts ${ }^{12}$ for the case of absorption with pseudo-first order reaction. 


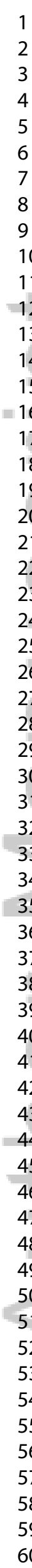

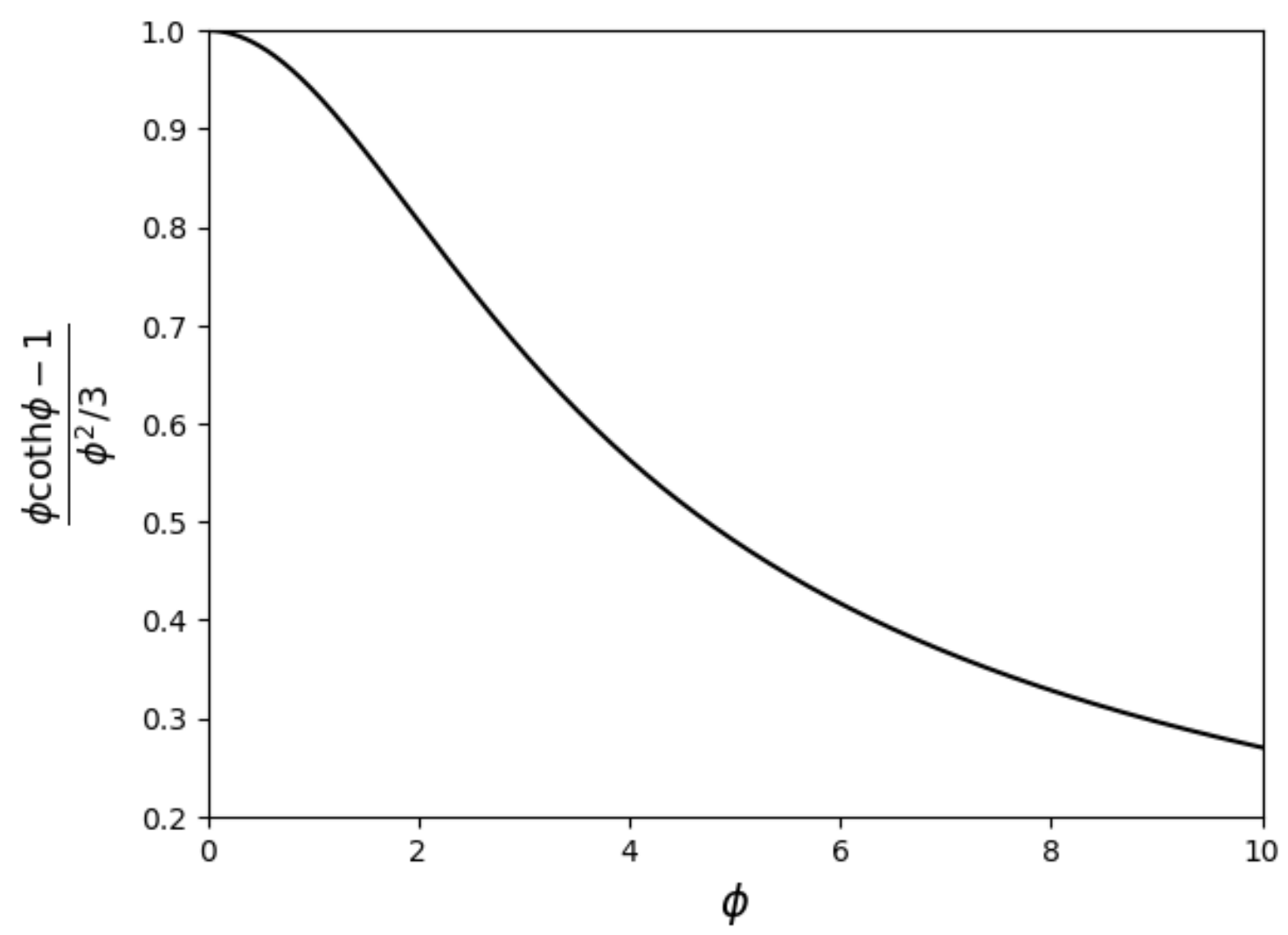

Figure 3: The influence of particle size, as quantified by the Thiele Modulus, on the specific absorption rate. 

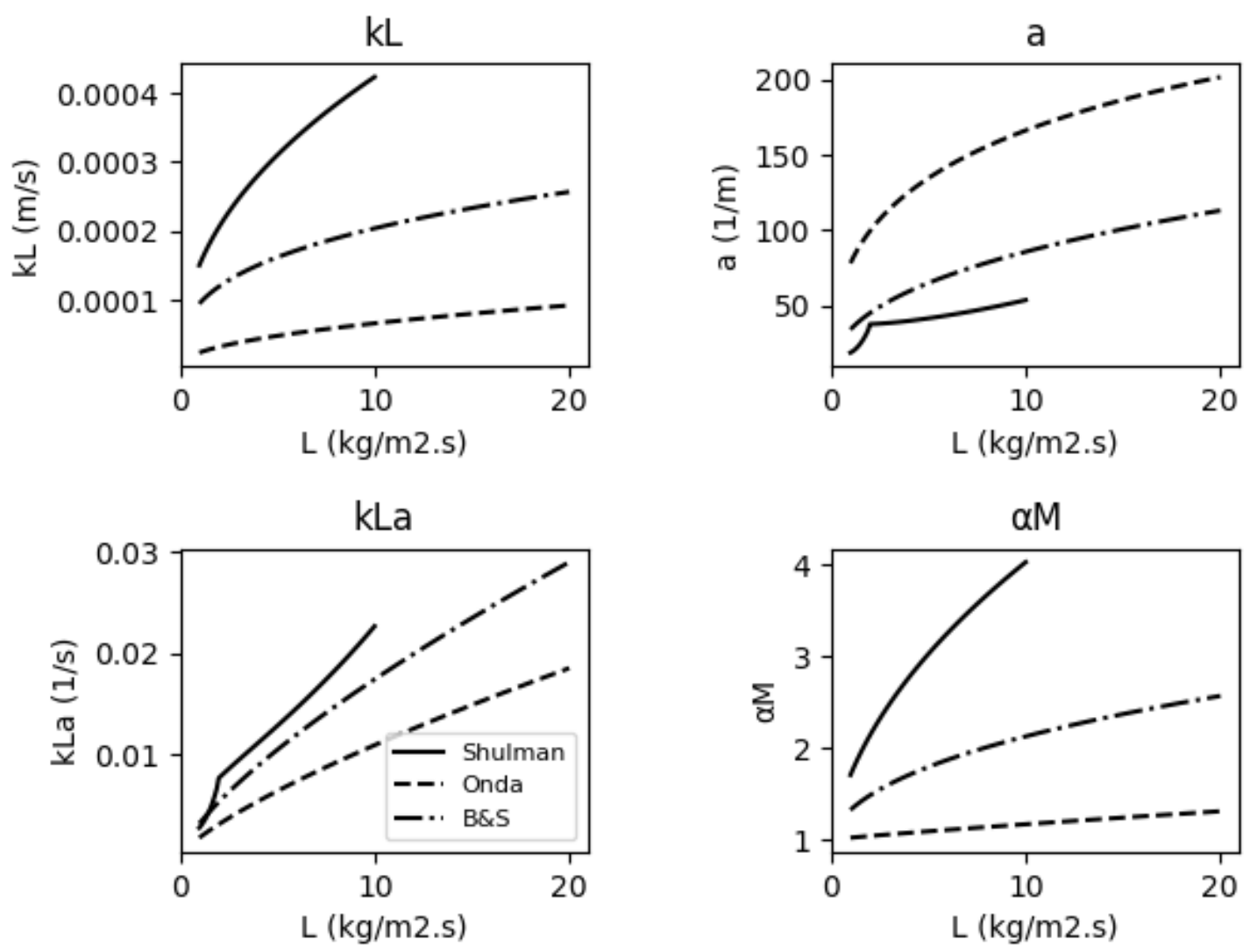

Figure 4: Values of $a, k_{L}, k_{L} a$ and $\alpha M$ for $30 \mathrm{wt} \% \mathrm{~K}_{2} \mathrm{CO}_{3}$ flowing down a packed column containing 1/2-inch Raschig Rings, as predicted by the correlations of Shulman et al., ${ }^{21}$ Onda et al. ${ }^{23}$ and Billet and Shultes. ${ }^{29}$ 

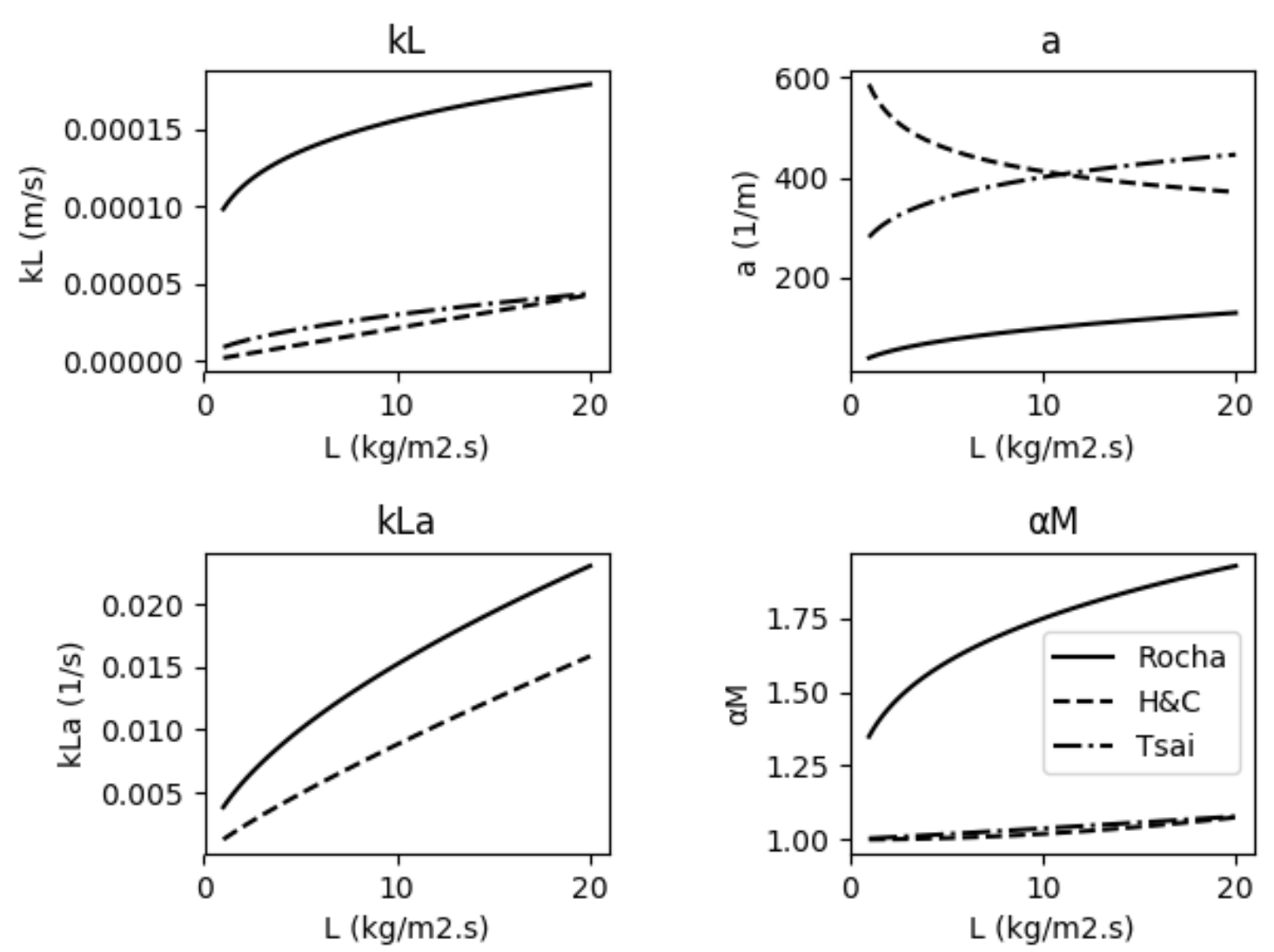

Figure 5: Values of $a, k_{L}, k_{L} a$ and $\alpha M$ for $30 \mathrm{wt} \% \mathrm{~K}_{2} \mathrm{CO}_{3}$ flowing down a packed column containing the structured packing Mellapak 500Y, as predicted by the correlations of Rocha et al., ${ }^{28}$ Hanley and Chen $^{27}$ and Tsai et al. ${ }^{30}$ Note that Tsai et al. only provides a prediction for $a$, so values of $k_{L}$ and $\alpha M$ were calculated based on the average of the $k_{L} a$ predictions of Rocha et al. and Hanley and Chen. 


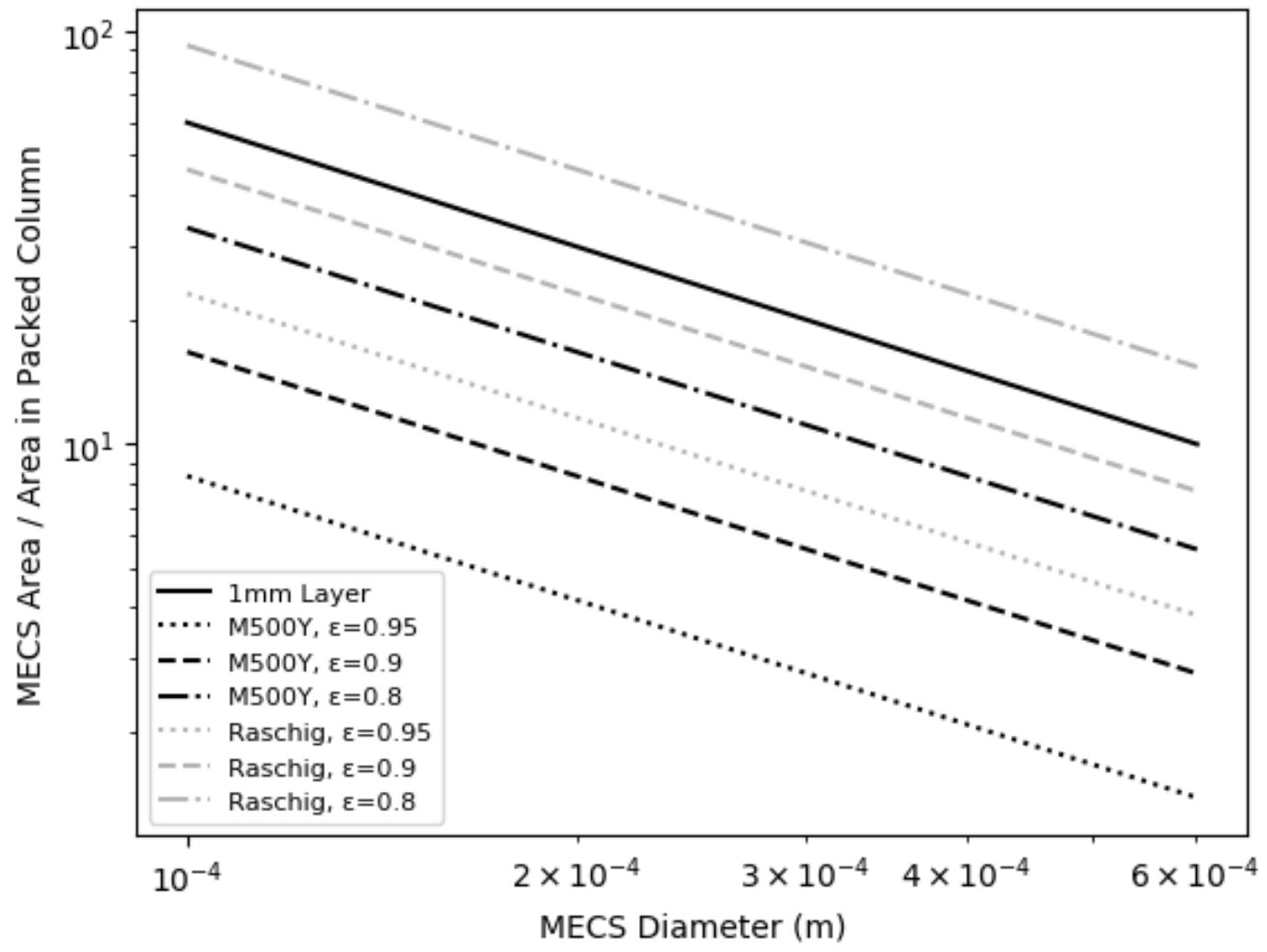

Figure 6: The increase in surface area on a unit volume of absorber basis which MECS can provide relative to a packed column, $a_{\mathrm{MECS}} / a$, plotted against particle diameter for various packing types. Also plotted is the increase in surface area per unit volume of solvent assuming a $1 \mathrm{~mm}$ thin layer of liquid in the packed column, $a_{\text {MECS }}^{\prime} / 1000 \mathrm{~m}^{2} \mathrm{~m}^{-3}$. M500Y: Mellapak 500Y. Raschig: 1/2 Inch Raschig Rings. $\varepsilon$ : voidage inside absorber containing MECS particles. Operating Conditions: $30 \mathrm{wt} \%$ $\mathrm{K}_{2} \mathrm{CO}_{3}$ flowing at $5 \mathrm{~kg} \mathrm{~m}^{-2} \mathrm{~s}^{-1}$. 


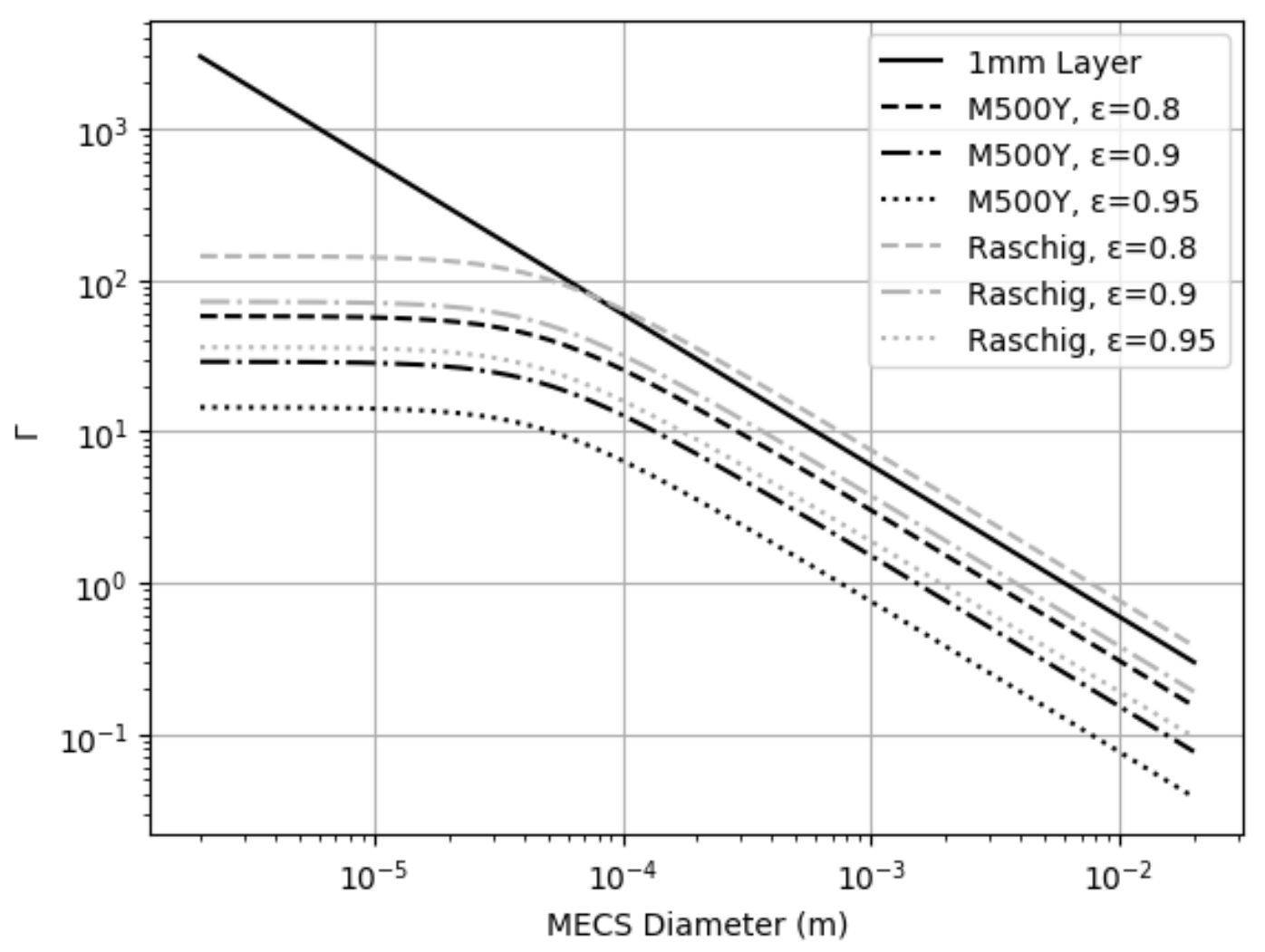

Figure 7: $\Gamma$ vs particle diameter for various packing types and values of $\varepsilon$. Also plotted is the increase in surface area per unit volume of solvent assuming a $1 \mathrm{~mm}$ thin layer of liquid in the packed column, $a_{\text {MECS }}^{\prime} / 1000 \mathrm{~m}^{2} \mathrm{~m}^{-3}$. M500Y: Mellapak 500Y. Raschig: 1/2 Inch Raschig Rings. $\varepsilon$ : voidage inside absorber containing MECS particles. Operating Conditions: $30 \mathrm{wt} \% \mathrm{~K}_{2} \mathrm{CO}_{3}$ flowing at $5 \mathrm{~kg} \mathrm{~m}^{-2} \mathrm{~s}^{-1}$. 


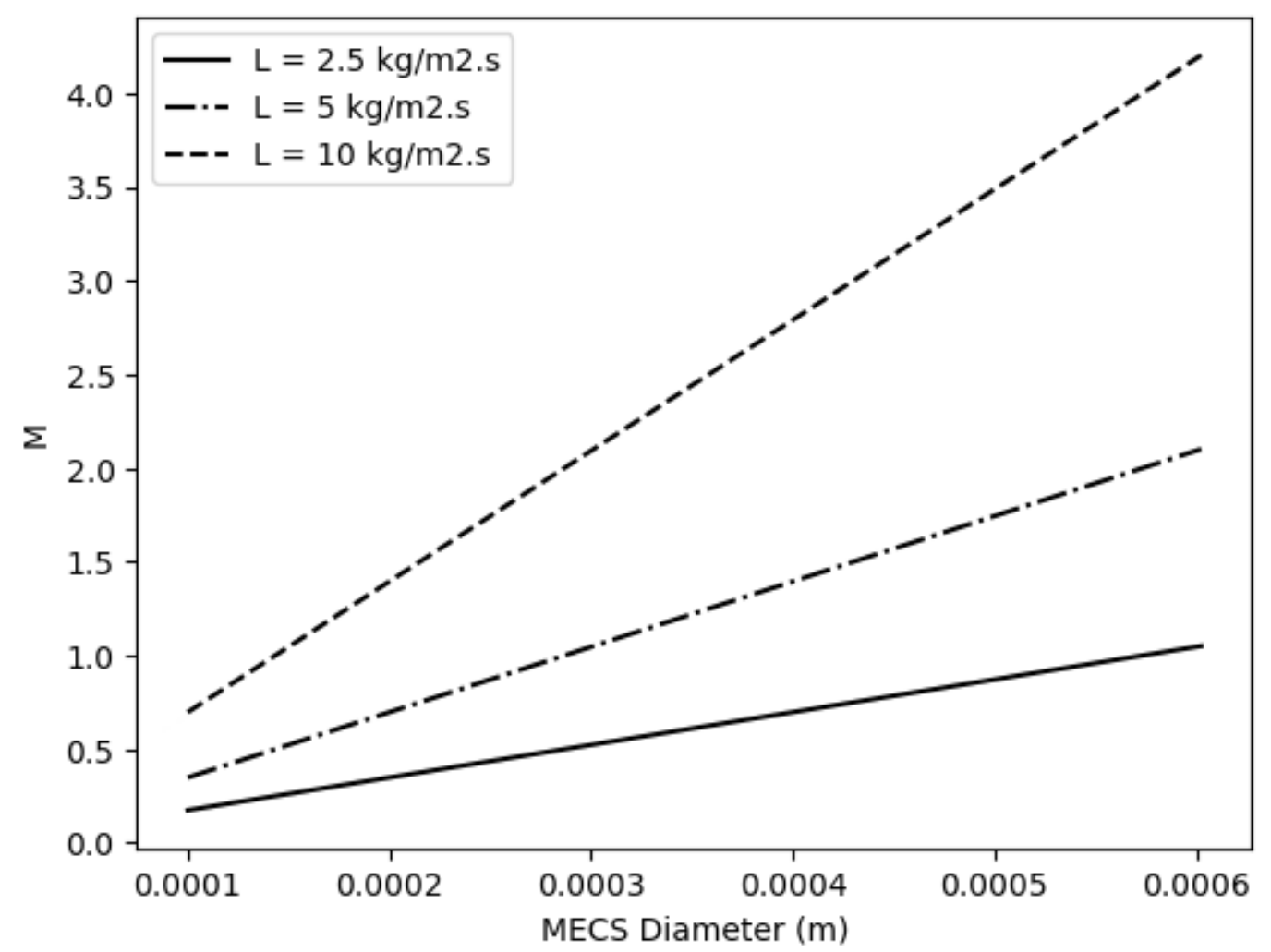

Figure 8: $M$ values for $\mathrm{CO}_{2}$ absorption into Selexol solvent as a function of particle radius, for various liquid flow rates, $L$, in the absorption column. Steel IMTP-40 packings are used. To maintain consistency with the chemical solvent case, a decrease in $M$ is associated with an increase in flux into the MECS particles, see Eq. (16). 


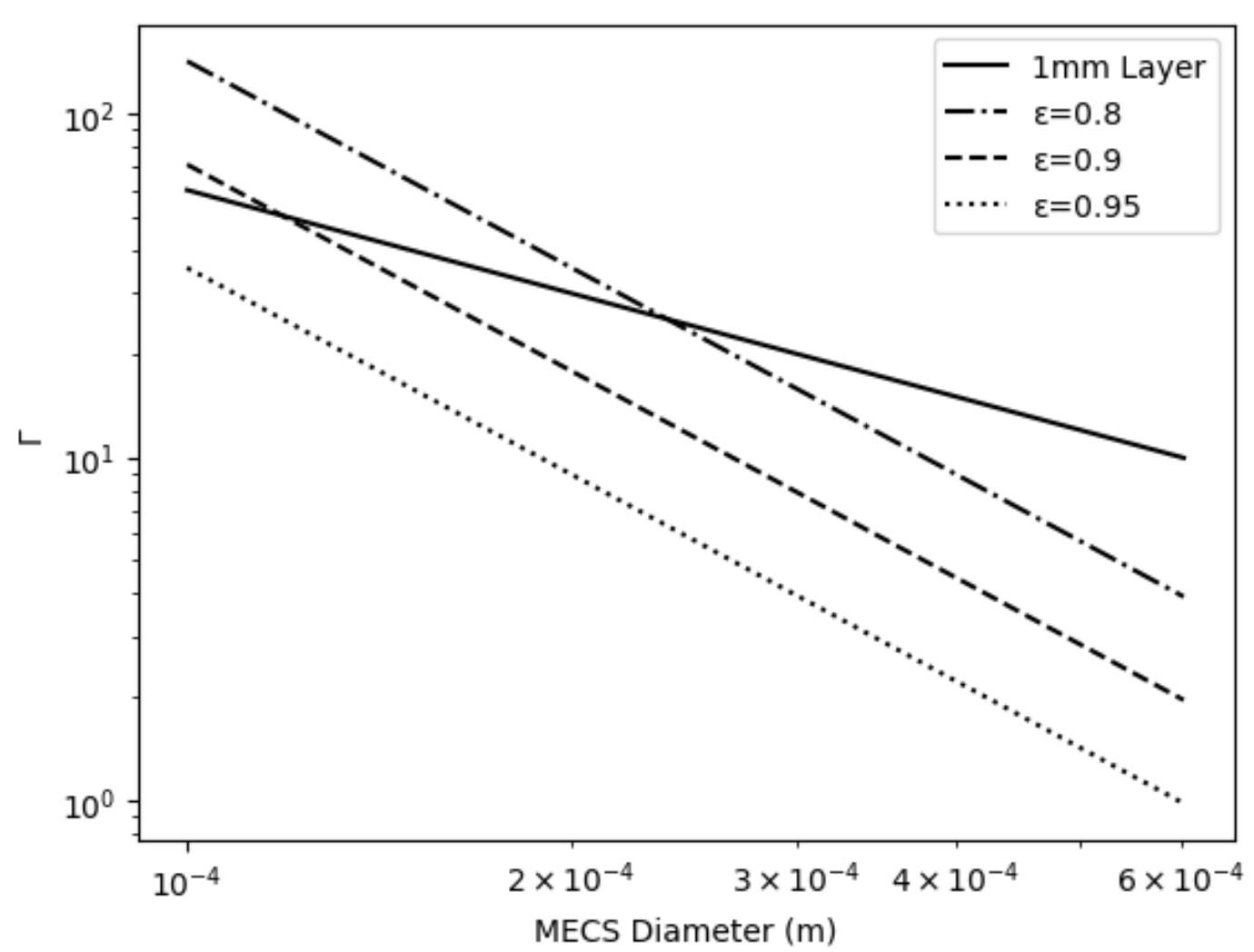

Figure 9: $\Gamma$ values for $\mathrm{CO}_{2}$ absorption into Selexol solvent as a function of particle radius, for various column voidages, $\varepsilon$, assuming $L=5 \mathrm{~kg} \mathrm{~m}^{-2}$. Steel IMTP-40 packings are used. 


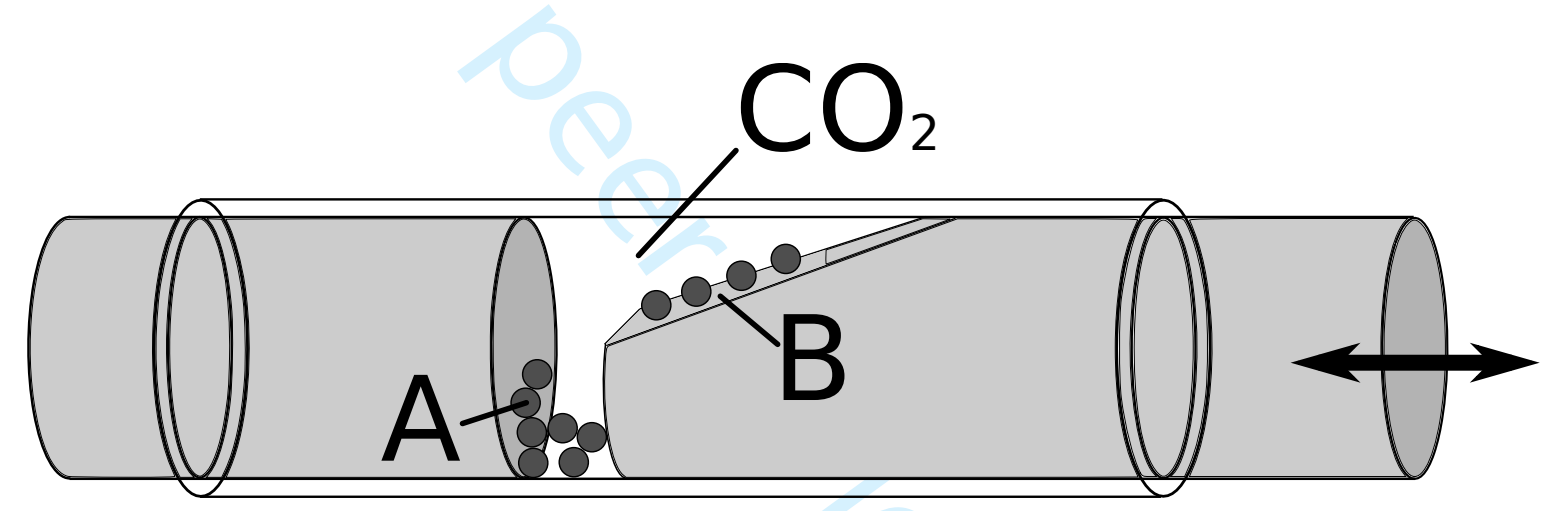

Figure 10: Testing the effect of particle compression on gas absorption. Particles in region A are crushed as the right piston is manually moved, while particles in region B are not compressed. Both regions are exposed to identical $\mathrm{CO}_{2}$ partial pressures, and gas uptake is monitored by observing particle colour change. 
Figure 11: MECS particles changing colour as they absorb $\mathrm{CO}_{2}$. The rate of colour change is identical for particles manually compressed between two glass plates (left) and uncompressed particles placed in the same gas environment. Compression frequency $\approx 2.5 \mathrm{~Hz}$, compressive strain $\approx 30-80 \%$. Please see online version for colour image. 


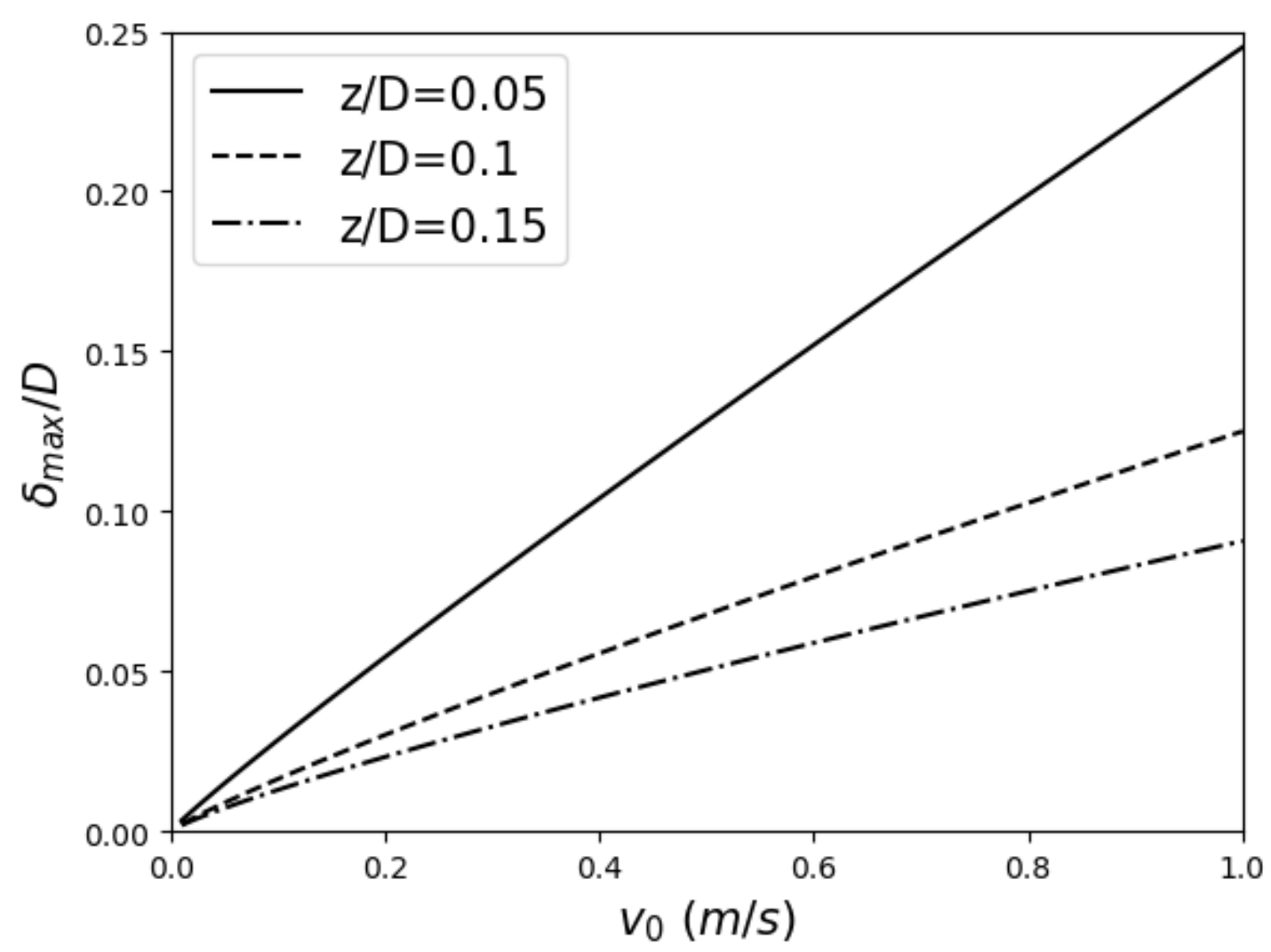

Figure 12: Maximum deformation of MECS particles during a collision with a wall, as a function of relative shell thickness, $z / D$, and particle velocity before the collision, $v_{0}$. 
Table 1: General-purpose correlations for the liquid-phase mass transfer coefficient and effective mass-transfer area.

$$
\begin{aligned}
& \text { Source } \\
& \text { Correlation } \\
& \text { Onda et al. }{ }^{23} \\
& k_{L}=0.0051\left(a_{t} d_{p}\right)^{0.4}\left(\frac{\mu g}{\rho}\right)^{1 / 3}\left(\frac{L}{a_{w} \mu}\right)^{2 / 3}\left(\frac{\mu}{\rho \mathscr{D}}\right)^{-1 / 2} \\
& \frac{a_{w}}{a_{t}}=1-\exp \left[-1.45\left(\frac{\sigma_{c}}{\sigma}\right)^{0.75}\left(\frac{L}{a_{t} \mu}\right)^{0.1} \times\left(\frac{L^{2} a_{t}}{\rho^{2} g}\right)^{-0.05}\left(\frac{L^{2}}{\rho \sigma a_{t}}\right)^{0.2}\right] \\
& \frac{k_{L} d_{s}}{\mathscr{D}}=25.1\left(\frac{d_{s} L}{\mu}\right)^{0.45}\left(\frac{\mu}{\rho \mathscr{D}}\right)^{0.5} \\
& a=q_{1}\left[\frac{808 G}{\sqrt{\rho_{G}}}\right]^{q_{2}} L^{q_{3}} \\
& k_{L}=q_{1}\left(\frac{\rho g}{\mu}\right)^{1 / 6}\left(\frac{\mathscr{D}}{d_{h}}\right)^{1 / 2}\left(\frac{L}{\rho a_{t}}\right)^{1 / 3} \\
& \frac{a}{a_{t}}=1.5\left(a_{t} d_{h}\right)^{-0.5}\left(\frac{L d_{h}}{\mu}\right)^{-0.2} \times\left(\frac{L^{2} d_{h}}{\sigma \rho}\right)^{0.75}\left(\frac{L^{2}}{g d_{h} \rho^{2}}\right)^{-0.45} \\
& \frac{k_{L} d_{e}}{\mathscr{D}}=q_{1}\left(\frac{d_{h} L}{\mu}\right)^{q_{2}}\left(\frac{\mu}{\rho \mathscr{D}}\right)^{q_{3}} \\
& \frac{a}{a_{t}}=q_{1}\left(\frac{\rho_{V}}{\rho}\right)^{q_{2}}\left(\frac{\mu_{V}}{\mu}\right)^{q_{3}} \times \operatorname{Re}_{L}^{q_{4}} F r_{L}^{q_{5}} W e_{L}^{q_{6}} \operatorname{Re}_{V}^{q_{7}}\left(\frac{\cos \theta}{\cos \pi / 4}\right)^{q_{8}} \\
& k_{L}=2\left(\frac{q_{1} \mathscr{D} L}{\pi S \rho \varepsilon h_{L} \sin \alpha}\right)^{1 / 2} \\
& \frac{a}{a_{t}}=F_{S E} \frac{29.12(W e \cdot F r)^{0.15} S^{0.359}}{R e^{0.2} \varepsilon^{0.6}(1-0.93 \cos \gamma) \sin ^{0.3} \alpha} \\
& \frac{a}{a_{t}}=1.34\left(\left(\frac{\rho}{\sigma}\right) g^{1 / 3}\left(\frac{L}{\rho} \frac{1}{L_{p}}\right)^{4 / 3}\right)^{0.116}
\end{aligned}
$$

$q_{i}$ are packing-dependent constants listed in Appendix III in the supplementary materials. 
Table 2: Physical Properties of $30 \mathrm{wt} \% \mathrm{~K}_{2} \mathrm{CO}_{3}$ solution at $313 \mathrm{~K}$.

\begin{tabular}{|c|c|c|}
\hline Parameter & Value & Source \\
\hline$\rho$ & $1286 \mathrm{~kg} \mathrm{~m}^{-3}$ & Sohnel and Novotny ${ }^{31}$ \\
\hline$\mu$ & $1.72 \times 10^{-3} \mathrm{Pas}$ & Correia et al. ${ }^{32}$ \\
\hline $\mathscr{D}$ & $1.0 \times 10^{-9} \mathrm{~m}^{2} \mathrm{~s}^{-1}$ & 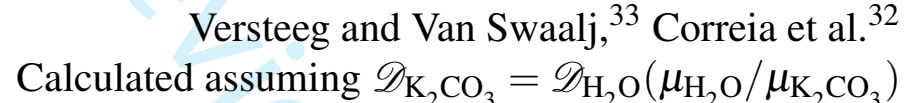 \\
\hline$\sigma$ & $0.087 \mathrm{~N} \mathrm{~m}^{-1}$ & Wilcox et al. \\
\hline$\sigma_{c}$ & $0.061 \mathrm{~N} \mathrm{~m}^{-1}$ & Wilcox et al. ${ }^{34}$ \\
\hline$k$ & $11.5 \mathrm{~s}^{-1}$ & Astarita, ${ }^{35}$ assuming $\mathrm{pH}=10$ \\
\hline
\end{tabular}


Table 3: Physical Properties of Selexol at $30^{\circ} \mathrm{C}$.

\begin{tabular}{rrr}
\hline Parameter & Value & Source \\
\hline$\rho$ & $1030 \mathrm{~kg} \mathrm{~m}^{-3}$ & Li et al. ${ }^{43}$ \\
$\mu$ & $6.35 \times 10^{-3} \mathrm{~Pa} \mathrm{~s}$ & Li et al. ${ }^{43}$ \\
$\mathscr{D}$ & $7.4 \times 10^{-10} \mathrm{~m}^{2} \mathrm{~s}^{-1}$ & Poling et al. ${ }^{44}$ \\
$\sigma$ & $0.035 \mathrm{~N} \mathrm{~m}^{-1}$ & Li et al. ${ }^{43}$ \\
$\sigma_{c}$ & $0.061 \mathrm{~N} \mathrm{~m}^{-1}$ & Wilcox et al. ${ }^{34}$ \\
$H$ & $1.5 \times 10^{-3} \mathrm{~mol} \mathrm{~Pa}^{-1} \mathrm{~m}^{-3}$ & Kohl and Nielsen \\
\hline
\end{tabular}


Table 4: Values of $k_{G} /\left(E H k_{L}\right)$ for various solvent systems.

\begin{tabular}{cr}
\hline System & $k_{G} /\left(E H k_{L}\right)$ \\
\hline Selexol, IMPT-40 & 194 \\
Unpromoted 30wt\% $\mathrm{K}_{2} \mathrm{CO}_{3}, \mathrm{pH}=9,1 / 2$-Inch Raschig Rings & 6395 \\
Unpromoted 30wt\% $\mathrm{K}_{2} \mathrm{CO}_{3}, \mathrm{pH}=10,1 / 2$-Inch Raschig Rings & 3160 \\
\hline
\end{tabular}




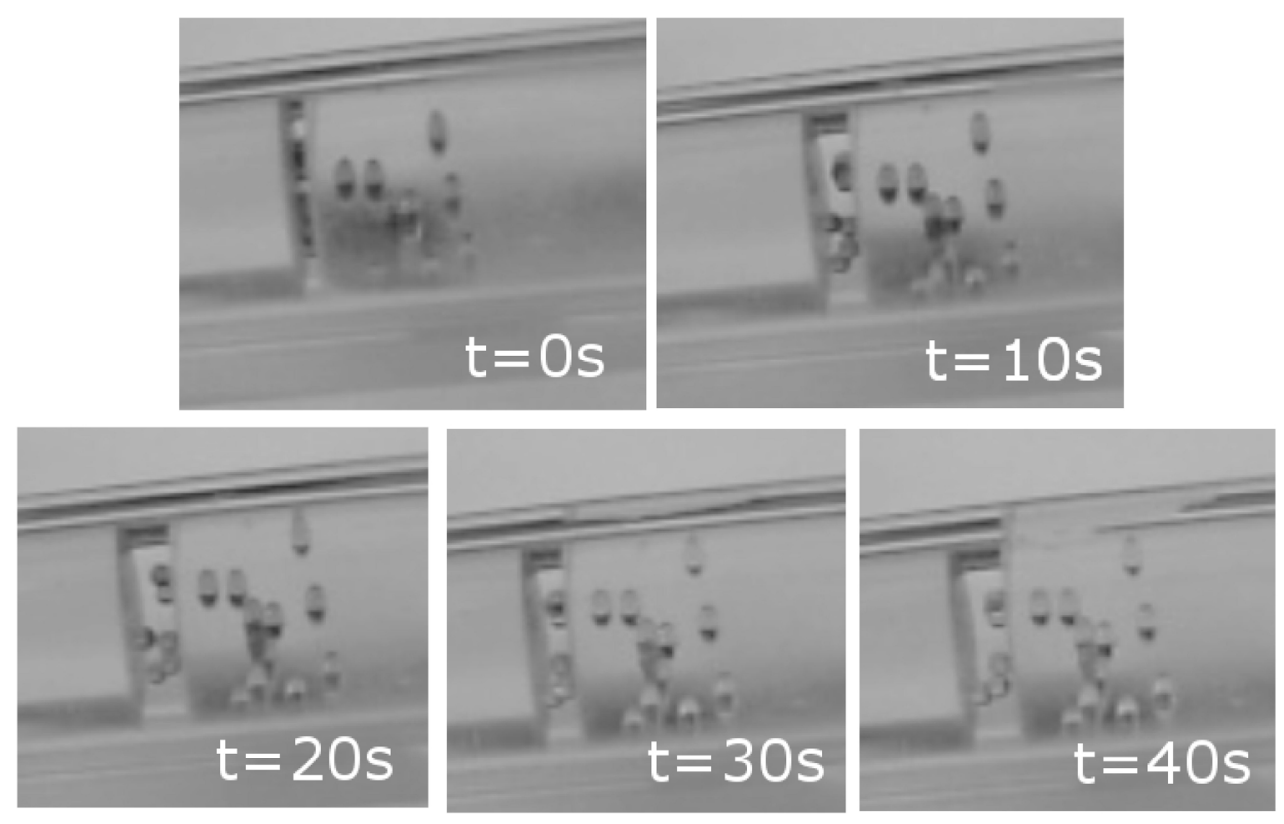

Black and White Version of Particle Crushing Image. $191 \times 135 \mathrm{~mm}(300 \times 300$ DPI $)$ 


\section{University Library}

\section{- M M I N E R VA A gateway to Melbourne's research publications}

Minerva Access is the Institutional Repository of The University of Melbourne

Author/s:

Moore, T;Mumford, KA;Stevens, GW;Webley, PA

Title:

Enhancement in Specific Absorption Rate By Solvent Microencapsulation

Date:

2018-11-01

Citation:

Moore, T., Mumford, K. A., Stevens, G. W. \& Webley, P. A. (2018). Enhancement in Specific Absorption Rate By Solvent Microencapsulation. AICHE JOURNAL, 64 (11), pp.4066-4079. https://doi.org/10.1002/aic.16366.

Persistent Link:

http://hdl.handle.net/11343/284498 